Prepared for the U.S. Department of Energy

under Contract DE-AC05-76RL01830

\title{
The Challenges and Potential of Nuclear Energy for Addressing Climate Change
}

SH Kim

J Edmonds

October 2007

Pacific Northwest

NATIONAL LABORATORY

Proudly Operated by Battelle Since 1965 


\title{
DISCLAIMER
}

This report was prepared as an account of work sponsored by an agency of the United States Government. Neither the United States Government nor any agency thereof, nor Battelle Memorial Institute, nor any of their employees, makes any warranty, express or implied, or assumes any legal liability or responsibility for the accuracy, completeness, or usefulness of any information, apparatus, product, or process disclosed, or represents that its use would not infringe privately owned rights. Reference herein to any specific commercial product, process, or service by trade name, trademark, manufacturer, or otherwise does not necessarily constitute or imply its endorsement, recommendation, or favoring by the United States Government or any agency thereof, or Battelle Memorial Institute. The views and opinions of authors expressed herein do not necessarily state or reflect those of the United States Government or any agency thereof.

\author{
PACIFIC NORTHWEST NATIONAL LABORATORY \\ operated by \\ BATTELLE \\ for the \\ UNITED STATES DEPARTMENT OF ENERGY \\ under Contract DE-AC05-76RL01830
}

Printed in the United States of America

Available to DOE and DOE contractors from the

Office of Scientific and Technical Information,

P.O. Box 62, Oak Ridge, TN 37831-0062;

ph: (865) 576-8401

fax: $(865) 576-5728$

email: reports@adonis.osti.gov

\footnotetext{
Available to the public from the National Technical Information Service, U.S. Department of Commerce, 5285 Port Royal Rd., Springfield, VA 22161 ph: (800) 553-6847 fax: $(703) 605-6900$

email: orders@ntis.fedworld.gov

online ordering: http://www.ntis.gov/ordering.htm
}

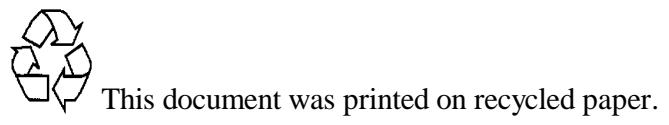




\title{
The Challenges and Potential of Nuclear Energy for Addressing Climate Change
}

October 2007

\author{
Son H. Kim \\ and \\ Jae Edmonds
}

The Joint Global Change Research Institute, Battelle, PNNL

8400 Baltimore Avenue, Suite 201

College Park, Maryland 20740-2496 


\begin{abstract}
The response to climate change and the stabilization of atmospheric greenhouse gas concentrations has major implications for the global energy system. Stabilization of atmospheric carbon dioxide $\left(\mathrm{CO}_{2}\right)$ concentrations requires a peak and an indefinite decline of global $\mathrm{CO}_{2}$ emissions. Nuclear energy, along with other technologies, has the potential to contribute to the growing demand for energy without emitting $\mathrm{CO}_{2}$. Nuclear energy is of particular interest because of its global prevalence and its current significant contribution, nearly $20 \%$, to the world's electricity supply.

We have investigated the value of nuclear energy in addressing climate change, and have explored the potential challenges for the rapid and large-scale expansion of nuclear energy as a response to climate change. The scope of this study is long-term and the modeling time frame extends out a century because the nature of nuclear energy and climate change dictate that perspective.

Our results indicate that the value of the nuclear technology option for addressing climate change is denominated in trillions of dollars. Several-fold increases to the value of the nuclear option can be expected if there is limited availability of competing carbon-free technologies, particularly fossil-fuel based technologies that can capture and sequester carbon. Challenges for the expanded global use of nuclear energy include the global capacity for nuclear construction, proliferation, uranium availability, and waste disposal. While the economic costs of nuclear fuel and power are important, non-economic issues transcend the issues of costs. In this regard, advanced nuclear technologies and new vision for the global use of nuclear energy are important considerations for the future of nuclear power and climate change.
\end{abstract}




\section{AKNOWLDGEMENTS}

We would like to thank Kathryn McCarthy at the Idaho National Laboratory for supporting this analysis and for promoting the greater understanding of nuclear technologies and their role in addressing climate change. 


\section{CONTENTS}

1 INTRODUCTION.................................................................................................1

2 APPROACH

3 A REFERENCE ENERGY FUTURE WITHOUT CLIMATE POLICY ......8 4 THE VALUE OF NUCLEAR TECHNOLOGY IN ADDRESSING

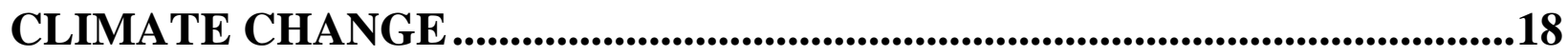

5 CHALLENGES FOR THE GREATER USE OF NUCLEAR ENERGY ....27

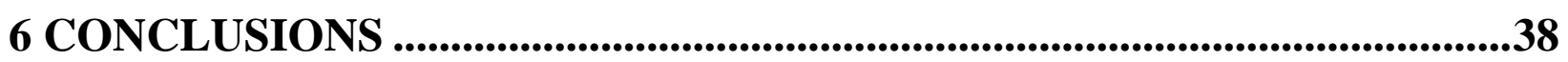




\section{1 \\ INTRODUCTION}

There is heightened interest in the greater use of nuclear energy worldwide as a potential solution to the climate change problem as the generation of electricity from nuclear power does not result in carbon emissions. The United States and 185 other nations and international organizations are members of the United Nations Framework Convention on Climate Change ${ }^{1}$ which has as its goal the stabilization of the atmospheric greenhouse gas concentrations at levels that would avoid dangerous human interference with the climate.

The implementation of this goal has major implications for the global energy system, because the stabilization of carbon dioxide concentrations $\left(\mathrm{CO}_{2}\right)$ is fundamentally different than the stabilization of traditional air pollutants. First, $\mathrm{CO}_{2}$ is well mixed in the atmosphere, and therefore, its concentration is determined by emissions from all sources everywhere. Beyond that, the concentration of $\mathrm{CO}_{2}$ is a function of cumulative emissions over time rather than annual emissions. Therefore, global $\mathrm{CO}_{2}$ emissions must peak and then decline indefinitely thereafter, ultimately becoming virtually zero, regardless of the concentration that is eventually deemed to prevent dangerous human interference with the climate. ${ }^{2}$

Human emissions of $\mathrm{CO}_{2}$ to the atmosphere in 2002 were estimated to be approximately 7.0 billion tons of carbon per year (BTC/y) from fossil fuel combustion ${ }^{3}$ and 1.7 BTC/y from landuse-change ${ }^{4}$. In the absence of greenhouse gas emissions limitations, the total global emissions could reach $20 \mathrm{BTC} / \mathrm{y}$ by the year 2100 , the median of emissions scenarios. ${ }^{5}$ For stabilizing $\mathrm{CO}_{2}$ concentrations at 550 parts per million (ppm), roughly double pre-industrial levels of $280 \mathrm{ppm}^{6}$, global $\mathrm{CO}_{2}$ emissions must peak between 2030 and 2035 at $11.2 \mathrm{BTC} / \mathrm{y}$ and decline thereafter along an emissions path that ultimately diminishes to zero. By the year 2100, global fossil fuel $\mathrm{CO}_{2}$ emissions must decline to less than their 2002 level. This in turn implies that between 500 and 650 exajoules per year (EJ/y) of fossil fuel emissions must be replaced with energy sources that have no $\mathrm{CO}_{2}$ emissions or with energy efficiency improvements. ${ }^{7}$ For comparison, global

\footnotetext{
${ }^{1}$ United Nations. 1992. Framework Convention on Climate Change. United Nations, New York.

${ }^{2}$ Wigley, T.M.L., R. Richels \& J. A. Edmonds. 1996. "Economic and Environmental Choices in the Stabilization of Atmospheric $\mathrm{CO}_{2}$ Concentrations," Nature. 379 (6562):240-243.

${ }^{3}$ Marland, G., T.A. Boden, and R. J. Andres. 2005. "Global, Regional, and National $\mathrm{CO}_{2}$ Emissions,” in Trends: A Compendium of Data on Global Change. Carbon Dioxide Information Analysis Center, Oak Ridge National Laboratory, U.S. Department of Energy, Oak Ridge, Tenn., U.S.A.

${ }^{4}$ Intergovernmental Panel on Climate Change (IPCC). 2001. Climate Change 2001: The Scientific Basis. The Contribution of Working Group I to the Third Assessment Report of the Intergovernmental Panel on Climate Change. J. T. Houghton, Y. Ding, D.J. Griggs, M. Noguer, P. J. van der Linden and D. Xiaosu (Eds.). Cambridge University Press, Cambridge, UK. pp 944.

${ }^{5}$ Nakicenovic, N. and R. Swart, eds. 2000. Special Report on Emissions Scenarios. Cambridge University Press, Cambridge, United Kingdom.

${ }^{6}$ Barnola, J.-M., D. Raynaud, C. Lorius, and N.I. Barkov. 2003. Historical CO2 record from the Vostok ice core. In Trends: A Compendium of Data on Global Change. Carbon Dioxide Information Analysis Center, Oak Ridge National Laboratory, U.S. Department of Energy, Oak Ridge, Tenn., U.S.A.

${ }^{7} 500$ and $650 \mathrm{EJ} / \mathrm{y}$ assumes that all emissions reduction in the year 2100 come from either coal or oil, respectively.
} 
energy consumption in 1990 was approximately $380 \mathrm{EJ} / \mathrm{y}$. Thus, the scale of change necessary for the stabilization of greenhouse gas concentrations holds profound implications for the shape of the global energy system.

A variety of technologies can be employed to provide energy services without $\mathrm{CO}_{2}$ emissions. Renewable energy forms such as wind, solar, and biomass-derived fuels could potentially be deployed at greater scale with technical and economic improvements. Increased end use efficiency can also provide the energy services society desires without emitting $\mathrm{CO}_{2}$. Fossil fuels can continue to be used if their associated $\mathrm{CO}_{2}$ emissions can be captured and stored. Nuclear energy is of particular interest because not only does it not emit $\mathrm{CO}_{2}$ in the creation of energy, but it is already a mature and significant contributor to the global energy system, supplying nearly $20 \%$ of the world's electricity. ${ }^{8}$

But nuclear power like all technologies must compete in a world in which economic performance matters. Fossil fuel technologies for power generation have evolved dramatically in recent years and the efficiency with which they transform fuels into electricity has risen. In a climate constrained world $\mathrm{CO}_{2}$ can potentially be captured and stored in geologic reservoirs. Other power generation options are also evolving.

Nuclear power technology has the potential to evolve as well. Present day nuclear technology is much improved over earlier generations and even reactors installed decades ago have benefited from technological advances. Nuclear technology can be expected to change and evolve as the future unfolds. Those technology developments will affect future deployment with or without climate policies. In this study, we investigate the role of advanced nuclear reactor and fuel systems in the context of global energy markets and the potential implications of climate change policy for nuclear technology.

We have developed long-term scenarios of the future global energy system with nuclear energy technologies to identify and understand key issues. Our focus is on the long term, because lead times in technology development, the long lifetime of nuclear technologies, and the nature of the climate issue dictate that perspective. Nevertheless, it is the implications of this strategic understanding for near-term decision making that motivates this analysis.

Our focus is on economic issues. We assume that non-economic issues such as concerns about safety, proliferation, and waste storage do not prevent nuclear energy from participating in the global energy market. However, as we explore the interaction of nuclear technology with markets, we remain cognizant of these concerns. One of the virtues of the approach we take is that it allows us to track fuel cycle implications. We can therefore comment on numbers of reactors deployed, waste materials produced, and the scale of fuels flowing through the system. Our principal focus will be on the scale and timing of nuclear technology and its implications for climate change.

\footnotetext{
${ }^{8}$ Energy Information Administration (EIA). 2005. Annual Energy Review 2004, US Department of Energy (DOE), Washington, D.C.
} 
We begin in Section 2 with a description of the $\mathrm{O}^{\mathrm{bj}}$ ECTS-MiniCAM model and its capability for modeling the nuclear energy system and the fuel cycle. In Section 3, we construct a reference scenario of the future evolution of the global energy system as it might occur in the absence of any policy intervention to address climate change. While this assumption is clearly counterfactual, we employ the assumption to provide a point of comparison with cases in which climate change policies are invoked. In the development of the Reference Scenario, we pay particular attention to the potential role of nuclear energy and competing technologies. In Section 4, the reference trajectory is then used to illustrate the impact of policies to address climate change on the market penetration of the nuclear energy including the competition from fossil-fuel technologies with carbon capture and storage (CCS). Several emissions constraints that stabilize the atmospheric $\mathrm{CO}_{2}$ concentration to $450,550,650$, and $750 \mathrm{ppm}$ are imposed on the Reference Scenario with and without the option for new nuclear deployment. Comparison of the cases with and without new nuclear deployment allows an estimation of the value of nuclear energy for mitigating $\mathrm{CO}_{2}$ emissions. A sensitivity case in which CCS technologies are unavailable explores the value of nuclear energy when options for emissions mitigation are limited. Section 5 investigates the potential challenges for nuclear energy particularly when the response to climate change may require a significantly expanded deployment in nuclear energy technologies. This section incorporates several sensitivity cases on the availability of uranium and cost of waste disposal. We discuss the issues of nuclear infrastructure and proliferation, uranium availability, accumulation of nuclear waste and disposal capacity, and new strategies for the use of nuclear energy as proposed by the US Global Nuclear Energy Partnership. The report is closed with concluding remarks in Section 6. 


\section{APPROACH}

In this analysis, we employ Pacific Northwest National Laboratory's $\mathrm{O}^{\text {bj }}$ ECTS (Object-oriented Energy, Climate, and Technology Systems) implementation of the MiniCAM integrated assessment model. ${ }^{9}$ The $\mathrm{O}^{\mathrm{bj}}$ ECTS-MiniCAM is a long-term, global integrated assessment model of energy-economy interactions and greenhouse gas ${ }^{10}$ (GHG) emissions. The model is disaggregated into 14 global regions. ${ }^{11}$ GHG emissions are tracked and the climate change consequences of changing concentrations of greenhouse related gases are calculated. The $\mathrm{O}^{\mathrm{bj}}$ ECTS-MiniCAM begins with a representation of demographic and economic developments in each of the 14 regions and combines these with assumptions about technology development to describe an internally consistent representation of energy, agriculture, land-use, and economic developments that shape global emissions and concentrations of GHGs. GHG concentrations in turn determine radiative forcing and climate change.

The structure of ObjECTS-MiniCAM is derived from the model described in Edmonds et al. with subsequent elaborations. ${ }^{12}$ While many integrated assessment models have simple representations of options for generating electric power, none have the capacity to describe both power generation technologies as well as the nuclear fuel cycle in the context of the long-term development of the global energy system. ObjECTS-MiniCAM has been enhanced to model technology vintages, and operation of technologies from new investments and existing vintages are separated. Each technology in the model has a lifetime, and once invested, technologies operate until their lifetime is exhausted or shut down if their variable costs exceed the market price of the produced good. In the work reported here, we make substantial improvements to the modeling of nuclear energy with particular emphasis on the treatment of the nuclear fuel cycle. The flexible nature of the ObjECTS framework for adding greater technology detail and market linkages significantly improves the richness in characterizing the nuclear energy system.

ObjECTS-MiniCAM model's ability to explore all aspects of the nuclear energy system in a global context has been expanded to include global uranium and other resources, nuclear fuel enrichment and fabrication sectors, advanced nuclear power technologies for electricity generation, and permanent nuclear waste disposal capacities. The expanded capability tracks

\footnotetext{
${ }^{9}$ Kim, SH, JA Edmonds, J Lurz, SJ Smith and M Wise. 2006. “The $\mathrm{O}^{\mathrm{bj}}$ ECTS Framework for Integrated Assessment: Hybrid Modeling of Transportation.” The Energy Journal, Special Issue \#2, 63-91.

${ }^{10} \mathrm{O}^{\mathrm{bj}}$ ECTS-MiniCAM tracks emissions of 15 greenhouse related gases: $\mathrm{CO}_{2}, \mathrm{CH}_{4}, \mathrm{~N}_{2} \mathrm{O}, \mathrm{NO}_{\mathrm{x}}, \mathrm{VOCs}, \mathrm{CO}, \mathrm{SO}$, carbonaceous aerosols, HFCs, PFCs, and $\mathrm{SF}_{6}$. Each is associated with multiple human activities that are tracked in $\mathrm{O}^{\mathrm{bj}}$ ECTS-MiniCAM.

${ }^{11}$ The United States, Canada, Latin America, Western Europe, Eastern Europe, the Former Soviet Union, the Middle East, Africa, India, China, Other South and East Asia, Australia and New Zealand, Japan, and South Korea.

${ }^{12}$ Edmonds, J. and J. Reilly. 1985. Global Energy: Assessing the Future, Oxford University Press, Oxford, United Kingdom; Edmonds J, Clarke K, Dooley J, Kim SH, Smith SJ. 2004. "Stabilization of $\mathrm{CO}_{2}$ in a B2 World: Insights on the Roles of Carbon Capture and Storage, Hydrogen, and Transportation Technologies," Energy Economics, 26:517-537; Hulme, M., S.C.B. Raper and T.M.L. Wigley. 1995. "An Integrated Framework to Address Climate Change (ESCAPE) and Further Developments of the Global and Regional Climate Modules (MAGICC)," Energy Policy, 23:347-355; Kim et al., see note 9.
} 
nuclear waste production and its composition. The model can track reprocessing of this waste for fissile and fertile material extraction and use as nuclear fuel and separation of minor actinides and fission products for waste minimization. Nuclear fuel costs include cost for ore, conversion, enrichment, fabrication, interim storage, waste disposal, and reprocessing if applicable. Figure 2-1 shows the schematic diagram of the expanded nuclear system modeling capability. The potential pathways of nuclear technology choice as represented by the linkages are evaluated independently or in combination to better understand the tradeoff among the different pathways. While the capability for modeling the nuclear energy system is comprehensive, not all potential pathways are utilized or explored in this particular analysis.

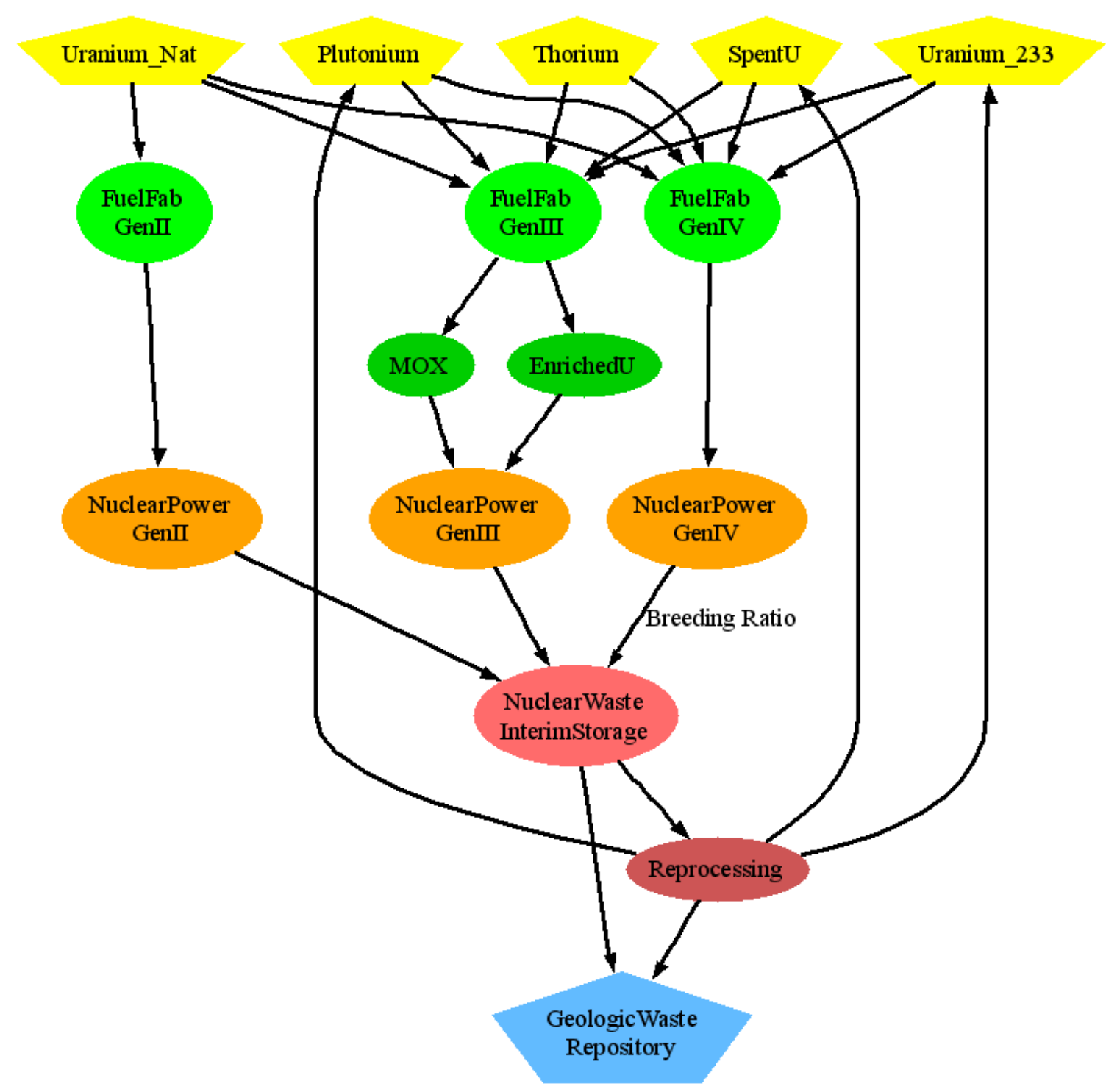

Figure 2-1

Schematic Diagram of the Nuclear Systems and Fuel Cycle Modeling in the $\mathbf{O}^{\mathrm{bj}}$ ECTS-MiniCAM Model 
Two groups of nuclear power technologies were included in this analysis: currently operational conventional light-water reactors and next generation advanced thermal neutron spectrum reactors. Both groups are assumed to utilize a once-through fuel cycle with direct disposal of spent fuel. These reactors are, in general, referred to as Gen II and Gen III reactors, respectively. The Gen III reactor category includes evolutionary advanced light-water reactors (LWR) and other advanced reactor designs with improved economics and safety features referred to as Gen III $+{ }^{13}$ The principal characteristics of all Gen III reactors are lower and more competitive capital costs and improved operating and safety features than conventional Gen II reactors. Few Gen III reactors are currently deployed but have great potential for near-term deployment. Gen IV refers to the next generation of advanced nuclear reactors and related technology systems that promote the long-term sustainable use of nuclear energy. ${ }^{14}$ This includes better utilization of nuclear fuels and resources, waste reduction strategies for minimizing geologic repositories needs, and improving safety, economics, and proliferation resistance of nuclear systems. Several concept reactors have been identified for the Gen IV system including thermal-spectrum and fast reactors with potential for breeding nuclear fuels, burning actinides, and producing hydrogen, in addition to generating electricity. While Gen IV technologies may play an important role in the future global energy system, we do not investigate their role in this report.

In a reference world, one without limitations on greenhouse gas emissions, the economic competition contains no premium for GHG emissions. On the other hand, in a world with GHG limitations, nuclear power has a relative cost advantage as it has no direct GHG emissions. ${ }^{15}$ But nuclear energy is not the only technology without direct $\mathrm{CO}_{2}$ emissions. Energy efficiency, wind, biofuels, and solar energy also have that characteristic. Furthermore, the deployment of CCS technologies could in principle facilitate the continued use of fossil fuels with substantially reduced emissions. With current research efforts on improving the cost of CCS technologies and demonstrating the capability of geologic storage, one might expect that CCS technology would be competitive in a world with a significant value of carbon. ${ }^{16}$ The character of CCS, renewable, biomass, and energy efficiency technologies will have an important influence on the degree to which nuclear energy captures market share.

\footnotetext{
${ }^{13}$ Magwood WD. 2000. "Roadmap to the Next Generation of Nuclear Power System: A Vision for a Powerful Future.” Nuclear News, November (2000).

${ }^{14}$ Nuclear Energy Research Advisory Committee and the Generation IV International Forum. 2002. "A Technology

Roadmap for Generation IV Nuclear Energy Systems,” December, U.S. Department of Energy.

${ }^{15}$ In a case in which emissions are limited, the cost of materials employed in building and operating a nuclear facility will be affected by the greenhouse gas emissions associated with those materials. The cost of cement for example would be affected not only by costs associated with energy-related $\mathrm{CO}_{2}$ emissions, but also by direct $\mathrm{CO}_{2}$ emissions.

${ }^{16}$ Freund, P and WG Ormerod. 1997. "Progress toward storage of carbon dioxide," Energy Conversion and

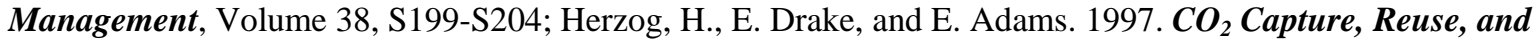
Storage Technologies for Mitigation Global Climate Change. MIT Energy Laboratory, MIT, Cambridge, MA; Edmonds J, Freund P, and JJ Dooley. 2002. "The role of carbon management technologies in addressing atmospheric stabilization of greenhouse gases,” in Williams DJ, Durie RA, McMullan P, Paulson CAJ and Smith YA editors. Greenhouse Gas Control Technologies, Proceedings of the Fifth International Conference on Greenhouse Gas Control Technologies, CSIRO, Collingswood, VIC, Australia. (2001):46-51; Dooley James J. and Friedman S.J. 2004. A Regionally disaggregated global accounting of $\mathrm{CO}_{2}$ storage capacity: data and assumptions. Battelle Pacific Northwest Division, PNWD-3431.
} 
In the $\mathrm{O}^{\mathrm{bj}}$ ECTS-MiniCAM model it is the relative economic performance of competing technologies that determines market share. As the economic performance of a technology improves, its market share grows. Economic performance depends both on the engineering characteristics of the technology and on the cost of inputs and products. Thus, fossil fuel production depends on both the extent and gradation of resources. Primary energy forms can be transformed into a wide array of fuels. Technologies employing energy carriers compete to provide energy services such as transportation, industrial energy, and building services. The deployment of nuclear power in the $\mathrm{O}^{\mathrm{bj}} \mathrm{ECTS}$-MiniCAM depends both on its own, absolute performance, and on the performance of competing technologies.

In our approach, we take up several issues along the way including the timing and scale of deployment in nuclear technology without climate change policy in the Reference Scenario. Comparison of multiple scenarios with and without nuclear technology and across a range of climate policies clarifies the implications of nuclear technology availability and its value in meeting a climate constraint. We explore the competition between nuclear power and alternative technologies in the electricity market and assess the potential challenges for the large-scale expansion of nuclear energy. 


\section{3}

\section{A REFERENCE ENERGY FUTURE WITHOUT CLIMATE POLICY}

The Reference Scenario used in this analysis is based the Scenario of Greenhouse Gas Emissions and Atmospheric Concentrations from the US Climate Change Science Program (CCSP) ${ }^{17}$. This recent and updated scenario incorporates the most up to date historical information and assumptions regarding future demographics, socioeconomic parameters, and energy use, and thus, employs an important reference baseline for long-term global energy and economic analysis. This does not necessarily make it a likely scenario. It is, however, within the range of many other scenarios that appear in the literature. The Reference Scenario assumes that nuclear fuel and power technology development is limited to that which is presently available. This is done, not because it is either expected or desired, but rather as an analytical device to provide a benchmark for understanding the role of current generation of nuclear technologies and to understand the potential challenges of the nuclear technology system.

In particular, the Reference Scenario developed as a baseline for the purposes of scenario comparison assumes direct disposal of spent fuel from nuclear reactors and that the capacity for nuclear waste disposal is not limited. Fixed costs for interim storage and permanent waste disposal, however, are included for all regions and modeled after the current US practice of charging a fee on the generation of nuclear electricity. Actual nuclear fuel and waste management practices currently vary across countries with France, United Kingdom, Germany, Japan, Russia, and others electing to reprocess their wastes, while USA, Canada, South Korea, Sweden, and others choosing direct disposal of their used fuels. ${ }^{18}$

A scenario is built up from a set of exogenously specified components. Some of the most important are population and technology performance. Population assumptions are displayed in Figure 3-1 Panel A (global total) and Figure 3-1 Panel B (population by region). This demographic profile shows a world in which global population peaks at approximately 9 billion in the year 2065 and declines to 8.7 billion by the end of the century as most of the population growth occurs before mid-twenty-first-century.

\footnotetext{
${ }^{17}$ Clarke L, J. Edmonds, H. Jacoby, H. Pitcher, J. Reilly, R. Richels. 2007. Scenarios of Greenhouse Gas Emissions and Atmospheric Concentrations. Climate Change Science Program Synthesis and Assessment Product 2.1, Part A, forthcoming.

${ }^{18}$ www.world-nuclear.org/info/inf04.htm
} 


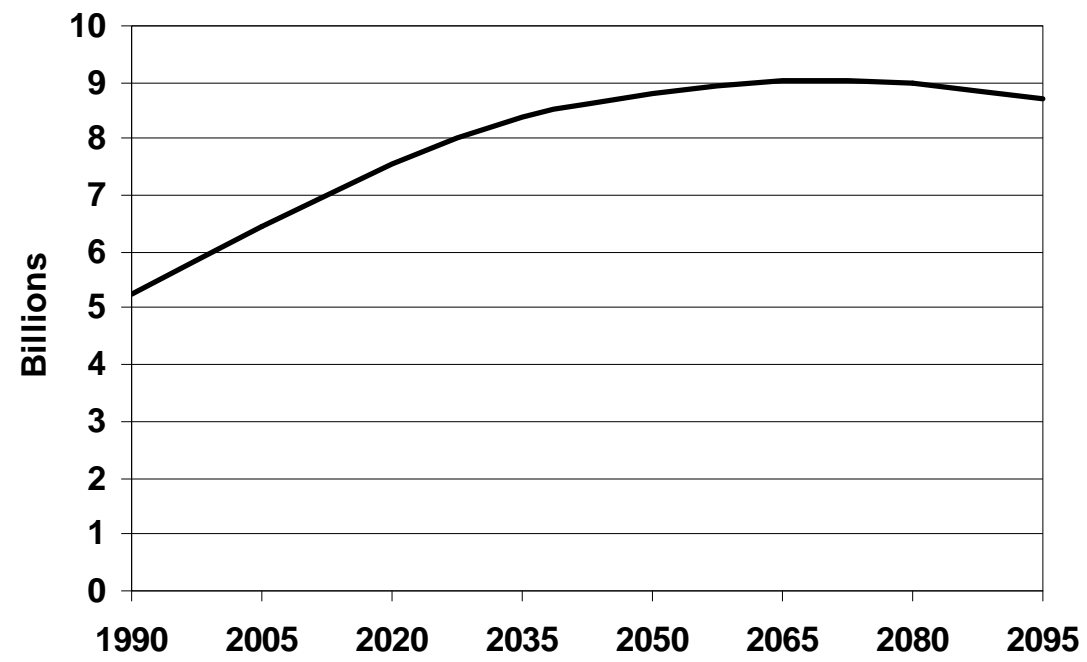

Figure 3-1 Panel A

Reference Scenario: Global Population (Billions of Persons)

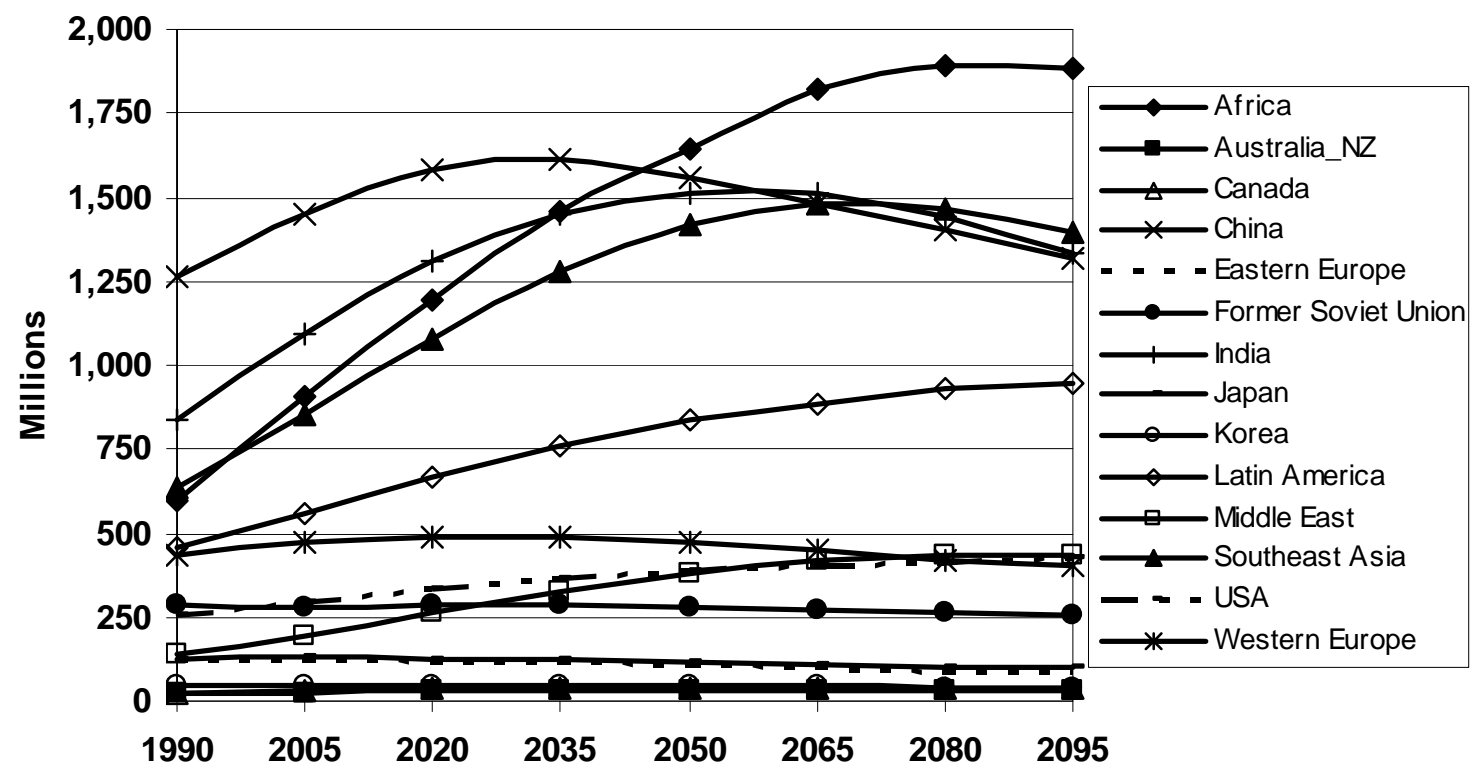

Figure 3-1 Panel B

Reference Scenario: Global Population by Region (Millions of Persons) 
Assumed nuclear fuel and reactor characteristics and costs are displayed in Table 3-1. Burnup and enrichment factors, and conversion, enrichment, fabrication, interim storage, and waste disposal costs are typical or central values available in the literature. ${ }^{19}$ In this study, the charge for nuclear waste disposal is assumed to be fixed at one mill/kWhr $(\$ 0.001 / \mathrm{kWhr})$ or approximately $400 \$ / \mathrm{kg}$ of spent fuel. ${ }^{20}$

We have created a generic Gen III technology for the purpose of modeling. Many designs are under consideration as potential candidates for next generation deployment. While the particular design(s) that ultimately enter and penetrate the market remain for the future to determine, we can still explore the implication of successful development and deployment of Gen III class of technologies. There is a wide range of construction costs, from $\$ 1,100$ per $\mathrm{kW}$ to $\$ 2,300$ per $\mathrm{kW}$, for nuclear reactors that are classified as Gen III. ${ }^{21}$ The costs that we have used for Gen III technologies are based on DOE EIA's representative cost of evolutionary LWR's. ${ }^{22}$ Legacy Gen II reactors do not compete for new capacity and no new investments in Gen II reactors can occur. Existing Gen II reactors are assumed to have life expectancy of 60 years so that by 2050 all Gen II reactors will have been retired.

\footnotetext{
${ }^{19}$ Deutch, J. and E. Moniz (Co-chairs). 2003. The Future of Nuclear Power: An Interdisciplinary MIT Study, Cambridge, Massachusetts Institute of Technology (Web: web.mit.edu/nuclearpower); Bunn, M., S. Fetter, J.P. Holdren, and B. van der Swaan. 2003. “The Economics of Reprocessing vs. Direct Disposal of Spent Nuclear Fuel.” Harvard University, Cambridge, MA.

${ }^{20}$ Bunn et al., see note 19.

${ }^{21}$ Energy Information Administration (EIA). 2007. Assumptions to the Annual Energy Outlook 2007, US Department of Energy (DOE), Washington, D.C., pp 90; The Economic Future of Nuclear Power, University of Chicago, 2004; Deutch and Moniz, see note 19.

${ }^{22}$ EIA (2007), see note 21.
} 
Table 3-1

Nuclear Fuel and Reactor Characteristics and Costs

\begin{tabular}{|c|c|c|c|}
\hline & Gen II & Gen III & Gen III \\
\hline Year & Legacy & 2005 & 2095 \\
\hline Burnup (GWd/MTHM) & 45 & 50 & 50 \\
\hline Uranium Ore Cost & Endogenous & Endogenous & Endogenous \\
\hline Conversion Cost ( $\$ / \mathrm{kgU})$ & 5 & 5 & 5 \\
\hline Enrichment Cost (\$/SWU) & 100 & 100 & 100 \\
\hline Enrichment (\%) & $4.08 \%$ & $4.51 \%$ & $4.51 \%$ \\
\hline Fuel Fabrication Cost ( $\$ / \mathrm{kgHM})$ & 250 & 250 & 250 \\
\hline Interim Storage Cost ( $\$ / \mathrm{kgHM})$ & 200 & 200 & 200 \\
\hline Waste Disposal Cost $(\$ / \mathrm{kgHM})$ & 400 & 400 & 400 \\
\hline Capital Overnight ( $\$ / \mathrm{kW})$ & Legacy & 2,080 & 1,732 \\
\hline O\&M Fixed $(\$ / \mathrm{kW})$ & Legacy & 63.88 & 63.88 \\
\hline O\&M Variable (mills/kWh) & Legacy & 0.47 & 0.47 \\
\hline Heatrate (Btu/kWh) & 10,400 & 10,400 & 10,400 \\
\hline Capacity Factor & 0.85 & 0.85 & 0.85 \\
\hline Lifetime (years) & 60 & 60 & 60 \\
\hline
\end{tabular}

Assumptions on the availability of natural uranium vary widely. ${ }^{23}$ In this analysis, we use a supply curve for natural uranium based on a generalized simple crustal model ${ }^{24}$ of the relationship between uranium abundance and concentration fitted to the resource estimates and costs from the IAEA Redbook ${ }^{25}$. This uranium supply curve, displayed in Figure 3-2, provides the global availability of uranium in million metric tons (MTU) as a function of price ( $\$ / \mathrm{kgU})$. We refer to this supply curve as the PPM-Cost Model (PPM). The availability of uranium at a given price from the PPM supply curve falls within the range of estimates derived by the Gen IV Fuel Cycle Crosscut Group (FCCG) ${ }^{26}$ and Deffeyes and MacGregor ${ }^{27}$. It is worth noting that the natural uranium supply curve is assumed to be continuous and that significant amounts of natural uranium are available beyond those estimates in the Redbook data in lesser concentrations but at higher costs. Any estimates of the future cost of undiscovered mineral resources, whether conventional or not, are speculative and the judicious selection of a particular model depends on how it will be used. Estimates of cost and of the practicality of recovery vary widely, however.

\footnotetext{
${ }^{23}$ Schneider, Erich and William Sailor. 2007. “Long Term Uranium Supply Estimates.” Nuclear Technology, LAUR-05-8879, forthcoming; Bunn et al., see note 19.

${ }^{24}$ Schneider and Sailor, see note 23.

${ }^{25}$ Redbook, 2003. Uranium 2003: Resource, Production and Demand, IAEA, Vienna, Austria and the OECD/NEA, Paris, France.

${ }^{26}$ US Department of Energy (DOE). 2002. Generation-IV Roadmap: Report of the Fuel Cycle Crosscut Group, pp. $1-28-1-30$.

${ }^{27}$ Deffeyes, Kenneth S. and Mac Gregor, Ian D. 1980. World Uranium Resources, Scientific American, Vol. 242, No 1.
} 
In our study, we assume that uranium resources are available if costs rise sufficiently high. Abundance and costs are open to question, a matter that we explore in a subsequent section.

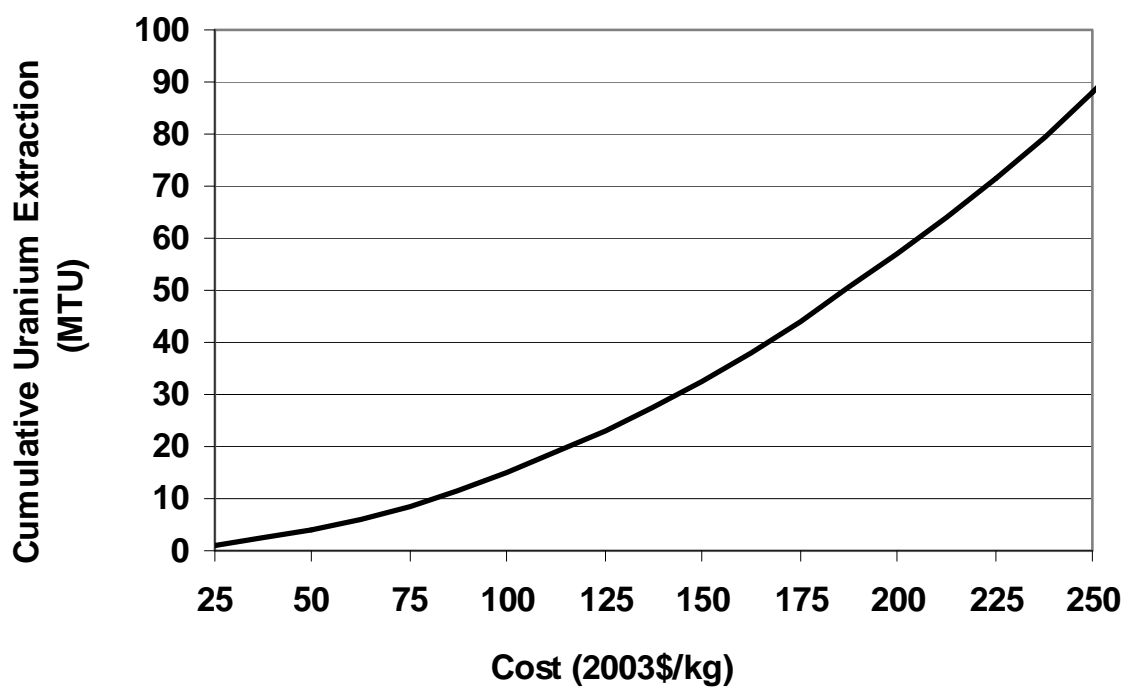

Figure 3-2

Natural Uranium Supply Curve (PPM Cost Model)

All technologies in the $\mathrm{O}^{\mathrm{bj}}$ ECTS-MiniCAM, including power technologies, compete for market share based on their levelized costs. Capital costs and their improvements are specified exogenously while fuel costs, whether fossil or nuclear, are determined endogenously. Power plant heat rates and annual capacity factors together with level costs of capital and O\&M (operations and management) determine the cost of electricity.

Technology assumptions for key competing energy technologies are given in Table 3-2. Capital costs, operations and management (O\&M) costs, and efficiencies are provided for fossil and biomass technologies. Fuel costs for these technologies are not displayed as they are determined endogenously by the model. Additional energy requirements and non-energy costs for fossil technologies with $\mathrm{CO}_{2}$ capture and storage are given, but they are not deployed absent a policy on the mitigation $\mathrm{CO}_{2}$ emissions. Solar costs shown include land, capital, and O\&M costs, but do not include the ancillary cost associated with reserve capacity. Although costs for wind technologies are not shown, power generation from wind is modeled regionally using two wind supply curves representing power generation from onshore and offshore resources. The supply curve includes the resource base and wind turbine costs. The two supply curves together provide the total amount of wind power available at a given electricity price. 
Table 3-2

Electric Power Technology Assumptions

\begin{tabular}{|c|c|c|c|}
\hline Technology & 2020 & 2050 & 2095 \\
\hline \multicolumn{4}{|c|}{ Electricity Cost (2000\$/MWhr) } \\
\hline Solar & 141 & 97 & 71 \\
\hline \multicolumn{4}{|c|}{ Capital \& O\&M Costs (2000\$/MWhr) } \\
\hline Pulverized Coal & 31 & 30 & 29 \\
\hline Coal (IGCC) & 33 & 31 & 29 \\
\hline Gas Turbine & 18 & 17 & 17 \\
\hline Gas (CC) & 14 & 13 & 12 \\
\hline Oil Turbine & 18 & 17 & 17 \\
\hline Oil (IGCC) & 30 & 28 & 26 \\
\hline Biomass & 14 & 14 & 13 \\
\hline Biomass (IGCC) & 15 & 14 & 14 \\
\hline \multicolumn{4}{|c|}{ Efficiency } \\
\hline Pulverized Coal & 0.41 & 0.42 & 0.44 \\
\hline Coal (IGCC) & 0.49 & 0.50 & 0.50 \\
\hline Gas Turbine & 0.40 & 0.41 & 0.43 \\
\hline Gas (CC) & 0.57 & 0.65 & 0.70 \\
\hline Oil Turbine & 0.40 & 0.41 & 0.43 \\
\hline Oil (IGCC) & 0.49 & 0.50 & 0.50 \\
\hline Biomass & 0.40 & 0.41 & 0.43 \\
\hline Biomass (IGCC) & 0.48 & 0.49 & 0.49 \\
\hline \multicolumn{4}{|c|}{ Carbon Capture Energy Requirement by Fuel ( $\mathrm{kWh} / \mathrm{kgC})$} \\
\hline Coal & 0.63 & 0.49 & 0.49 \\
\hline Gas & 1.23 & 1.09 & 1.09 \\
\hline Oil & 0.89 & 0.79 & 0.79 \\
\hline \multicolumn{4}{|c|}{ Additional Non-energy Cost for Carbon Capture $(2000 \$ / \mathrm{kgC})$} \\
\hline Coal & 0.030 & 0.028 & 0.028 \\
\hline Gas & 0.083 & 0.078 & 0.078 \\
\hline Oil & 0.060 & 0.056 & 0.056 \\
\hline
\end{tabular}

Fossil fuel resources are abundant, though not all grades of fossil fuel resources are abundant. We model them, as we do uranium, as a depletable graded resource. For fossil fuels, graded resources and their extraction costs are estimated for each modeling region. While the abundance of conventional oil and gas is limited, unconventional forms of these resources are extremely abundant. The most important question therefore is the distribution of resources across grades. Approximately 18,000 EJ ( 3000 billion barrels) of conventional oil is assumed with significantly more unconventional oil available around \$55-70/bbl. About $6000 \mathrm{EJ}$ proved, 13,500 EJ estimated additional sources, and another 16,000 EJ unconventional natural gas is 
assumed. Potentially several hundred thousand EJ of natural gas exists in hydrates. The distribution of coal resources across grades is not an interesting issue as the abundance in conventional grades is so great that resources and resource grades provide no meaningful limit on coal use. Total recoverable coal is estimated at over 250,000 EJ.

Thus, there are two fundamentally different fossil fuel scenarios that can be constructed. ${ }^{28}$ In one case, conventional oil and gas remain limited and unconventional liquids and gases remain expensive. In this case the global energy system can continue to use fossil fuels by transitioning to liquids and gases derived from coal. In the other case, technological change shifts oil and gas resources from the unconventional category to the conventional category. The scenarios employed here assume the gradual transformation of oil and gas resources from unconventional to conventional categories.

The global energy system is pushed forward by demographic, technology and economic assumptions. The scale of global economic activity increases over the course of the century by almost an order of magnitude, Figure 3-3.

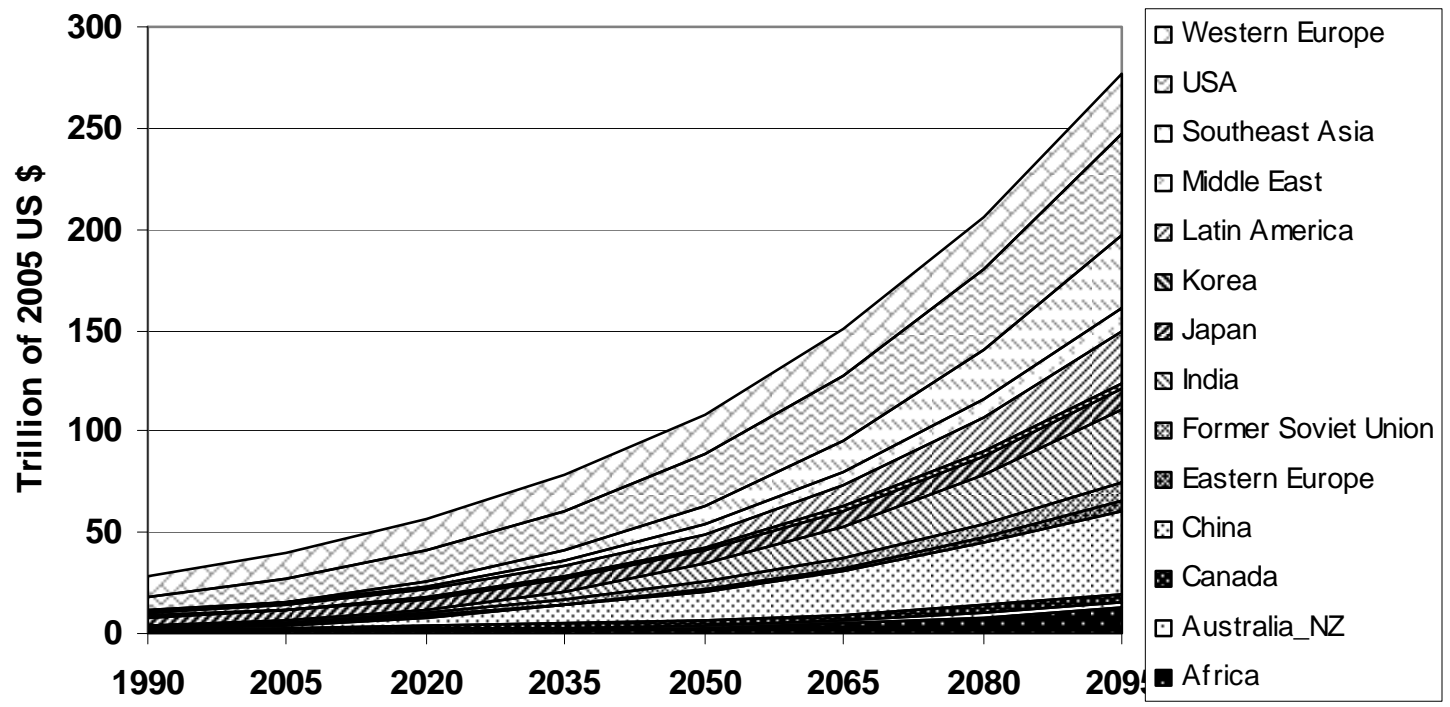

Figure 3-3

Gross World Product by Region (Trillions of 2005 US \$)

This in turn leads to growth in primary energy consumption from $380 \mathrm{EJ}$ in 1990 to $1400 \mathrm{EJ}$ in 2095, Figure 3-4. In the Reference Scenario, fossil fuel use remains central to the global energy system. By the end of the century, unconventional oil, which is composed of shale oil, natural bitumen and heavy crude oil, become the dominant source of liquid fuels.

\footnotetext{
${ }^{28}$ Edmonds, J.A., T. Wilson, and R. Rosenzweig. 2001. A Global Energy Technology Strategy Project Addressing Climate Change: An Initial Report an International Public-Private Collaboration. Joint Global Change Research Institute, College Park, MD.
} 


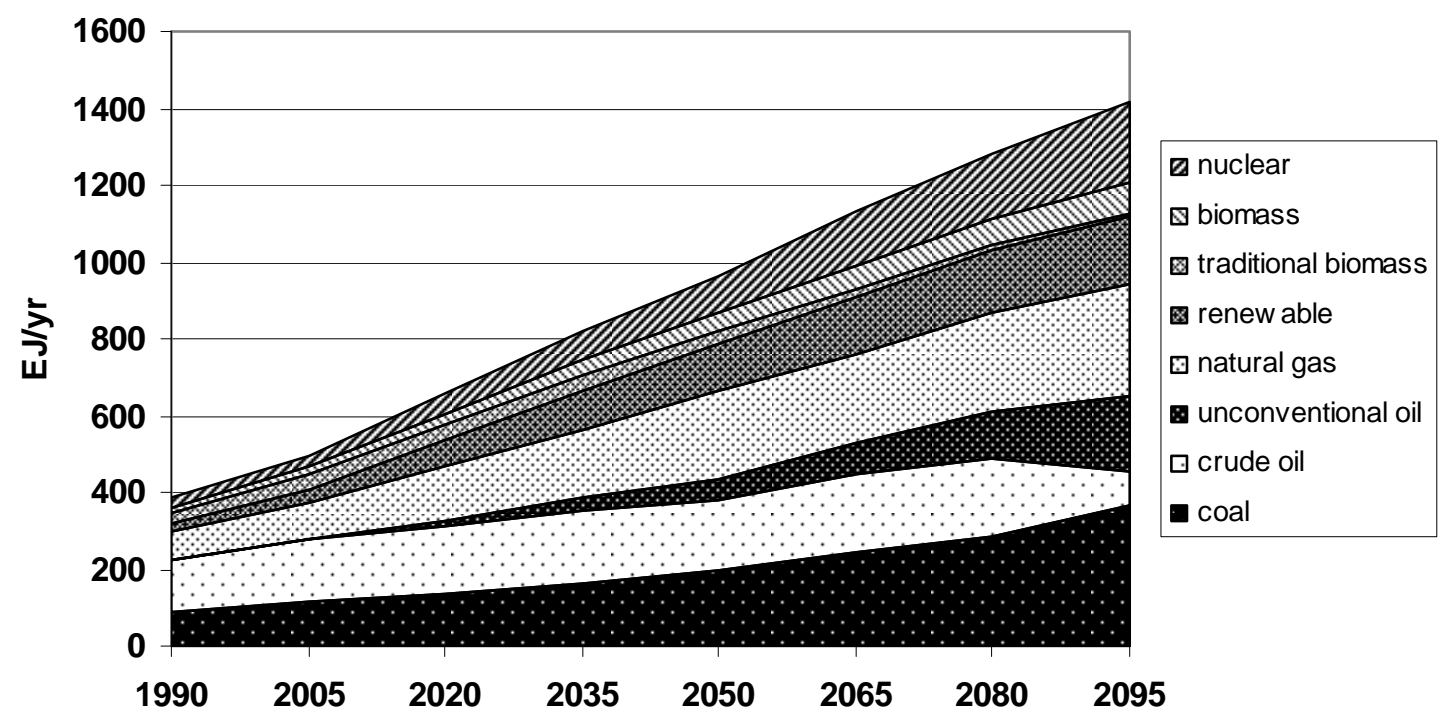

Figure 3-4

Global Primary Energy Consumption by Fuel (Reference Scenario)

Electric power consumption grows even faster than primary energy consumption, increasing from about $40 \mathrm{EJ}^{29}$ in 1990 to more than $300 \mathrm{EJ}$ by the end of the $21^{\text {st }}$ century, Figure 3-5.

Nuclear power transitions from Gen II to Gen III technology and expands as uranium resources and nuclear waste disposal are not constraints on nuclear technology deployment. By 2050, 30 EJ of nuclear energy or more than 1,100 reactors ${ }^{30}$ have been deployed globally representing 16 percent of the power market, Figure 3-6. By 2095, 68 EJ of nuclear energy or more than 2,500 reactors have been deployed comprising 22 percent of the global power market.

By the end of the century, cumulative uranium production will have exceeded 25 million metric tons. The cost of uranium has risen steadily to just above $\$ 130 / \mathrm{kg}$. Despite the high cost of uranium, nuclear power remains competitive because capital and fuel fabrication account for the bulk of the cost in generating nuclear electricity. The once-through fuel cycle does produce significant waste streams, and over the course of the century nearly 2.4 million tons of spent fuel is produced from all reactors worldwide. The accumulated waste does not include the implied additional waste production from the significant number of reactors deployed before but operating beyond the end of the century.

\footnotetext{
${ }^{29}$ An EJ is equal to 278 TWhr of electricity.

${ }^{30}$ Each reactor is assumed to be 1000 MWe in size with an annual capacity factor of 0.85 and lifetime of 60 years.
} 


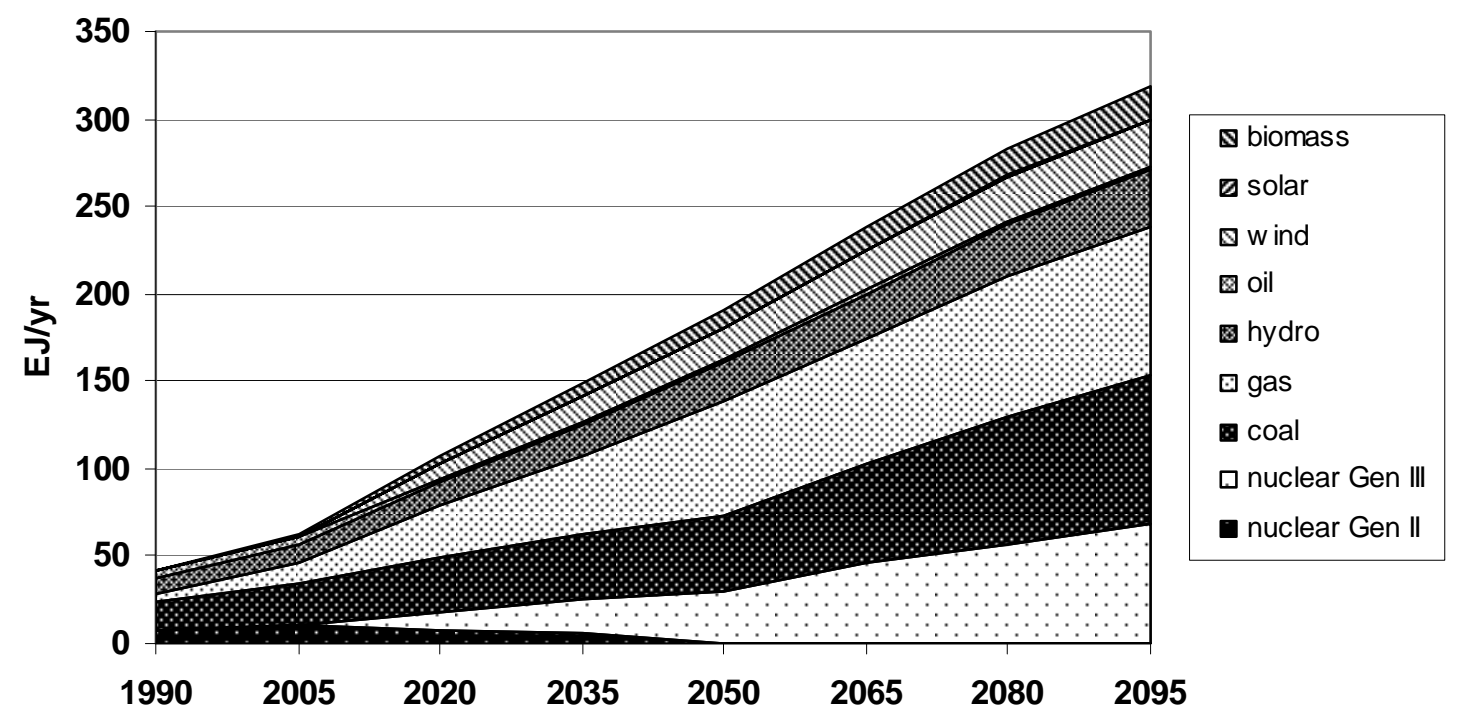

Figure 3-5

Global Electricity Generation (Reference Scenario)

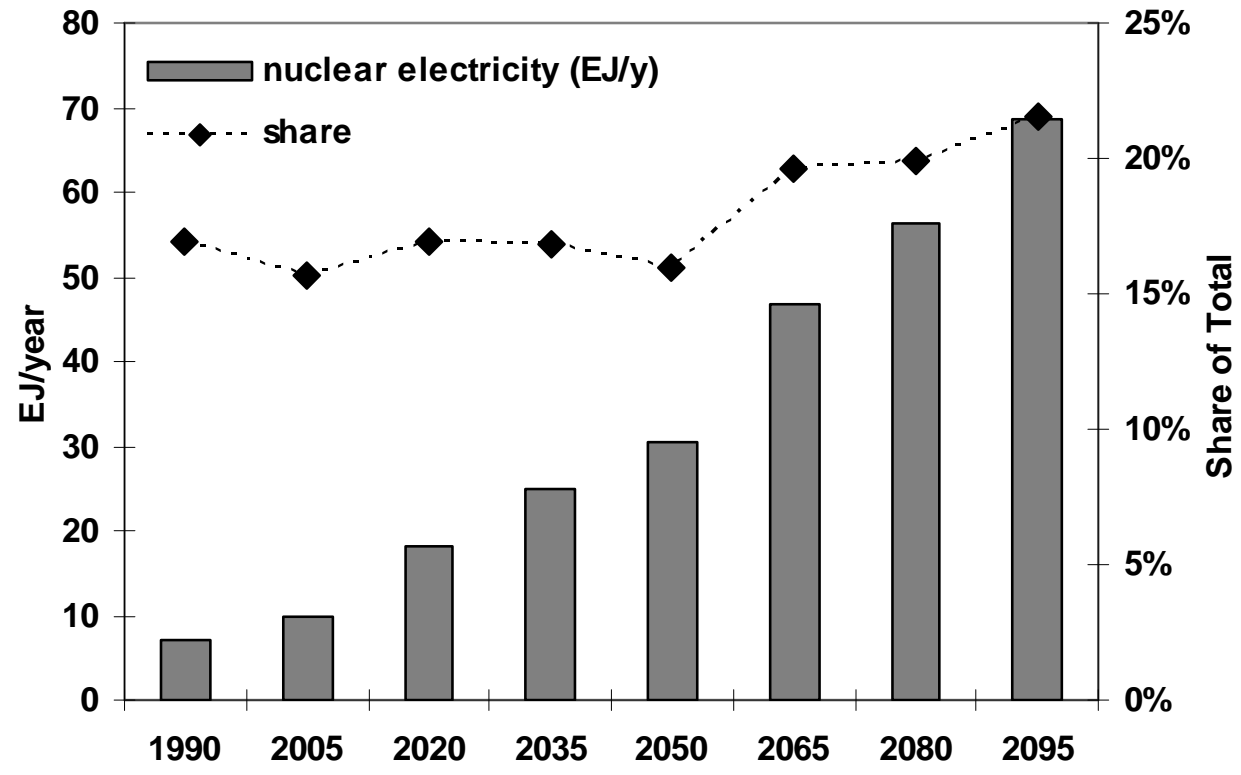

Figure 3-6

Global Nuclear Electricity Generation (EJ/y) and Share of Total (Reference Scenario)

Significant deployment of fossil-fueled power plants occurs. Fossil fuels remain the backbone of both the global energy system and power generation. Nuclear power maintains its share of the market, but coal and natural gas remain competitive. This leads to growing fossil fuel $\mathrm{CO}_{2}$ 
emissions, as shown in Figure 3-7. By 2095, annual fossil fuel $\mathrm{CO}_{2}$ emissions have grown to approximately 21 BTC, a 3.5 times increase over the 1990 emissions.

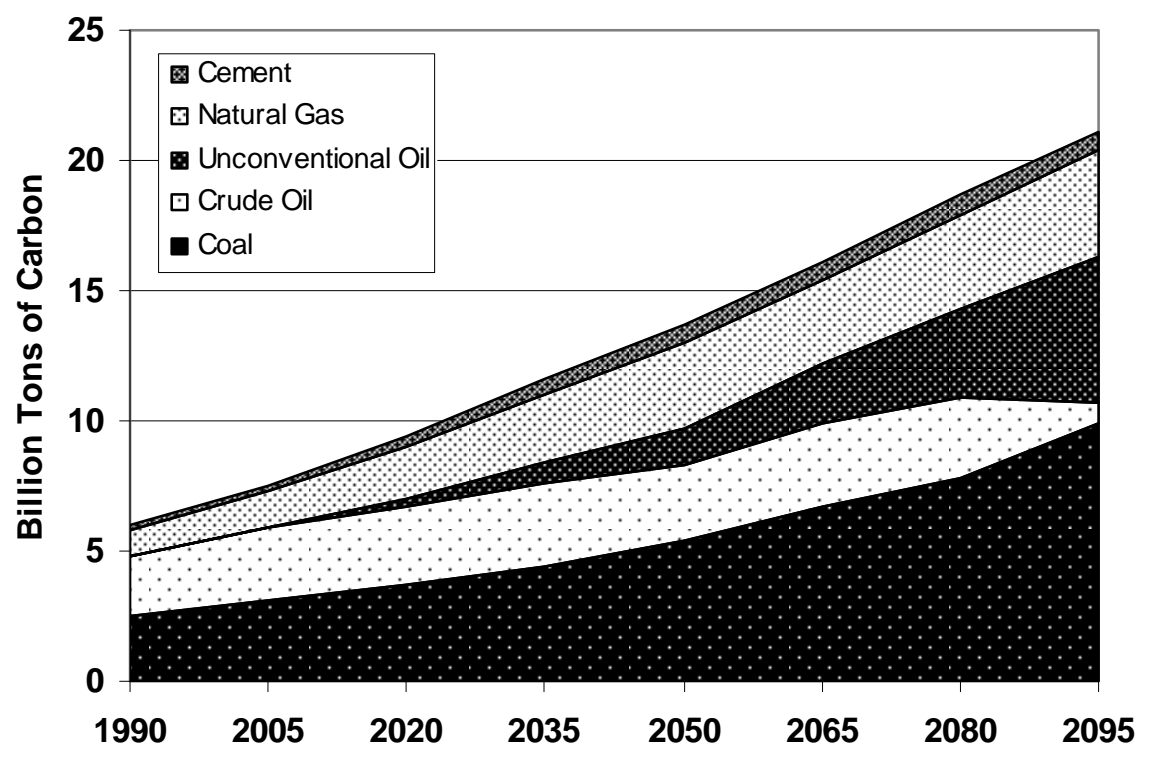

Figure 3-7

Global Fossil Fuel Carbon Emissions (Reference Scenario) 
4

\section{THE VALUE OF NUCLEAR TECHNOLOGY IN ADDRESSING CLIMATE CHANGE}

The $\mathrm{CO}_{2}$ stabilization scenario is the same as the Reference Scenario except that idealized policies are imposed to stabilize the concentration of $\mathrm{CO}_{2}$. We examine four alternative concentrations: $450 \mathrm{ppm}, 550 \mathrm{ppm}, 650 \mathrm{ppm}$ and $750 \mathrm{ppm}$ because there is no scientific consensus as to the $\mathrm{CO}_{2}$ concentration at which stabilization should occur. ${ }^{31}$ Stabilization of the concentration of $\mathrm{CO}_{2}$ is achieved by limiting global $\mathrm{CO}_{2}$ emissions to a path that minimizes the global discounted cost of stabilization. ${ }^{32}$ These are displayed in Figure 4-1.

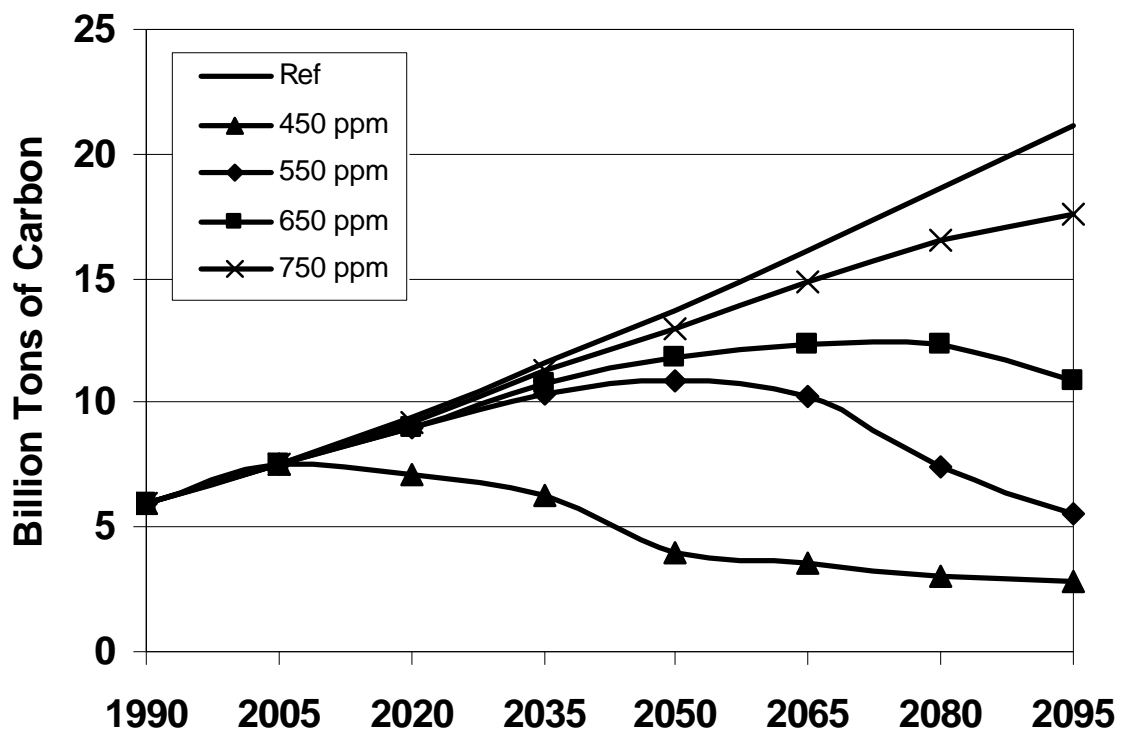

Figure 4-1

Global $\mathrm{CO}_{2}$ Emissions Paths for the Stabilization of Atmospheric $\mathrm{CO}_{2}$ Concentrations (Reference, $450 \mathrm{ppm}$, $550 \mathrm{ppm}, 650 \mathrm{ppm}$ and $750 \mathrm{ppm})$

The emissions limitation is affected by imposing a global carbon tax across all of the world's economies. All regions participate in imposing an economy-wide carbon tax beginning at the same time, with no sources of emissions that are exempt. The price of carbon follows along the

\footnotetext{
${ }^{31}$ The preindustrial concentration of $\mathrm{CO}_{2}$ is estimated to have been $280 \mathrm{ppm}$ and the concentration of $\mathrm{CO}_{2}$ in 2005 is estimated to be approximately $380 \mathrm{ppm}$.

${ }^{32}$ Peck, SC and YH Wan. 1996. "Analytical Solutions of Simple Greenhouse Gas Emission Models.” Chapter 6 of Economics of Atmospheric Pollution, eds EC Van Ierland and K Gorka. Springer Verlag, New York; Hotelling, H. 1931. “The Economics of Exhaustible Resources.” Journal of Political Economy 39: 137-175.
} 
Hotelling-Peck-Wan price path that is economically efficient over time resulting in minimum global discounted costs for the stabilization of $\mathrm{CO}_{2}$ concentrations. ${ }^{33}$ The carbon tax begins at a low rate and increases at the rate of interest modified by the rate of carbon uptake by the ocean and terrestrial sinks from the atmosphere. How large the tax becomes depends on how great the emissions mitigation must be at the end of the century and the set of technology options for emissions mitigation available to society. Of course, the assumption of a global carbon tax, charged uniformly around the world is unrealistic; its principal virtue is that it implies a minimum cost for achieving a particular goal. Real world emissions limitation regimes would almost certainly incur larger costs. Carbon taxes for all $\mathrm{CO}_{2}$ concentration targets with advanced nuclear and CCS technologies are shown in Figure 4-2.

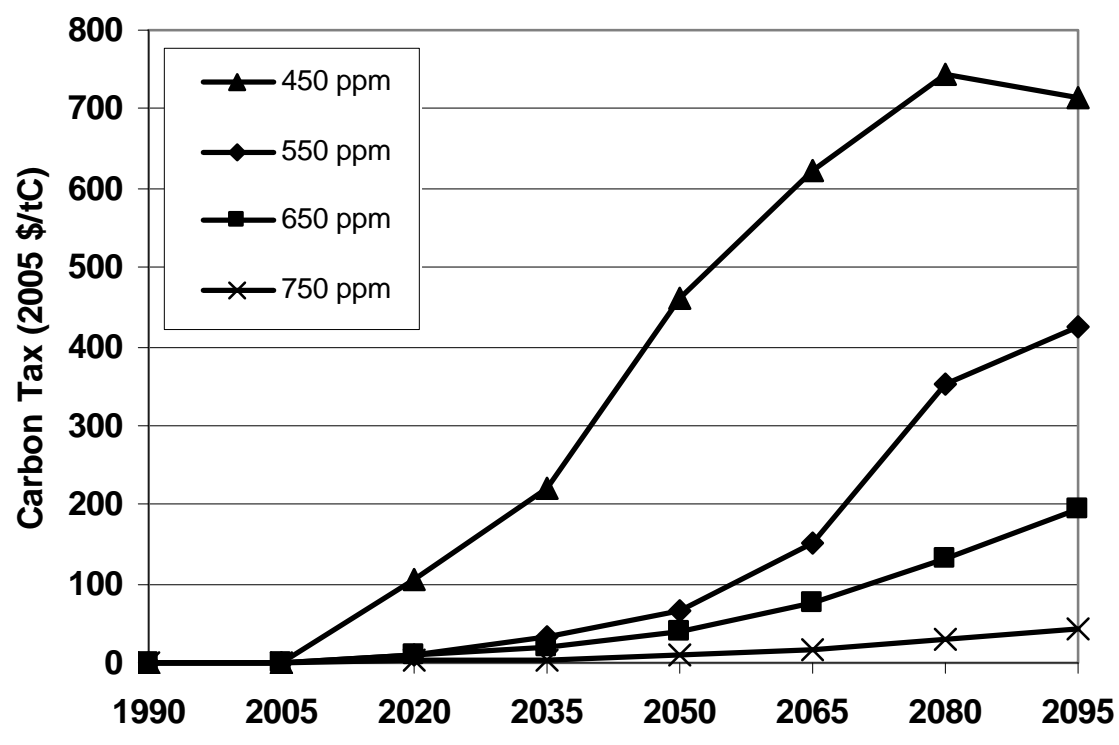

Figure 4-2

Carbon Taxes for Stabilizing $\mathrm{CO}_{2}$ Concentrations (450, 550, 650, and $\left.750 \mathrm{ppm}\right)$

Stabilization of $\mathrm{CO}_{2}$ concentrations, with its concurrent carbon values, dramatically affects the deployment of nuclear technologies in power generation. The deployment of nuclear technologies nearly doubles that of the Reference Scenario by the end of the century in the 450 ppm Scenario. As displayed in Figure 4-4 Panel A, more nuclear electricity is utilized globally as the $\mathrm{CO}_{2}$ concentration for stabilization becomes increasingly stringent. For the 750, 650 and $550 \mathrm{ppm}$ scenarios, the levels of nuclear power deployment do not depart significantly from the Reference Scenario until after 2035. However, achieving the lower concentration of $450 \mathrm{ppm}$ requires nearly immediate departure in nuclear deployment from today. The corresponding market shares of nuclear electricity generation are shown in Figure 4-4 Panel B. Nuclear power shares range from 22 to 37 percent of the global power market by 2095 depending on the $\mathrm{CO}_{2}$ concentration targets.

\footnotetext{
${ }^{33}$ See Peck and Wan (1996) which elaborates on the original approach developed by Hotelling (1931), see note 32.
} 
It is worth noting that although uranium prices and thus nuclear fuel costs move higher with time, uranium resources provide no meaningful constraint on the deployment nuclear power. We explore the implications of limits to the uranium resource base in Section 5 of the report.

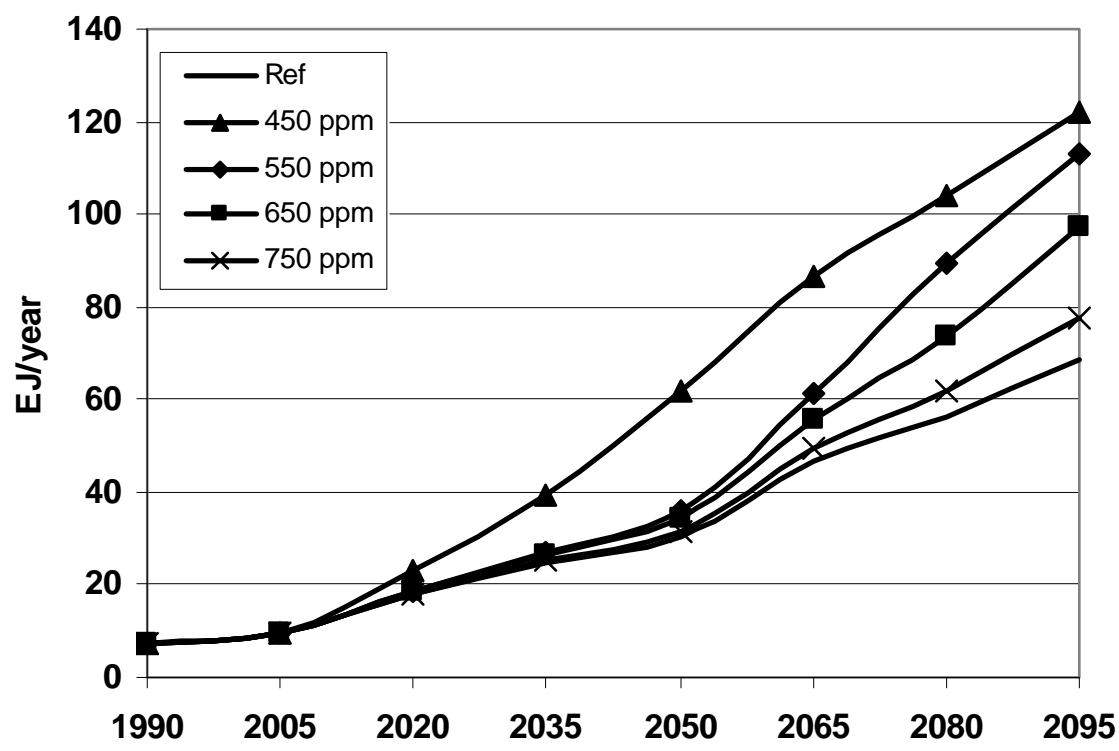

Figure 4-3 Panel A

Global Nuclear Electricity Generation for Alternative $\mathrm{CO}_{2}$ Concentration Stabilization Scenarios (Reference, and 450, 550, 650, and $750 \mathrm{ppm})$

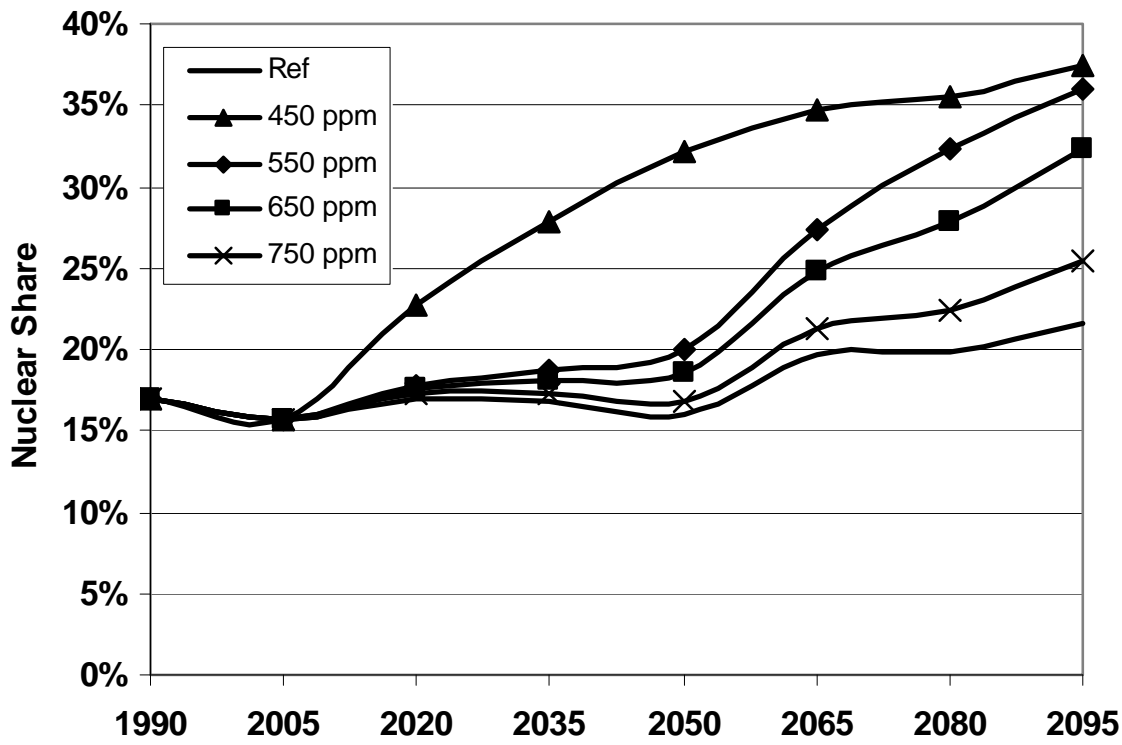

Figure 4-3 Panel B

Nuclear's Share of Global Electricity Generation for Alternative $\mathrm{CO}_{2}$ Concentration Stabilization Scenarios (Reference, and 450, 550, 650, and 750 ppm) 
While the market share of nuclear power grows dramatically in the presence of a climate constraint, fossil fuel CCS technologies become competitive and share the market for power. We display the mix of power technologies for one stabilization scenario, the $550 \mathrm{ppm} \mathrm{CO}_{2}$ concentration, in Figure 4-4. Fossil fuel use for power generation continues with the implementation of CCS technologies, but fossil fuel use, particularly natural gas and coal, with free venting of $\mathrm{CO}_{2}$ emissions are phased out. Wind and some additional commercial biomass make its way into the market, but the bulk of power deployment becomes nuclear and fossil technologies with CCS.

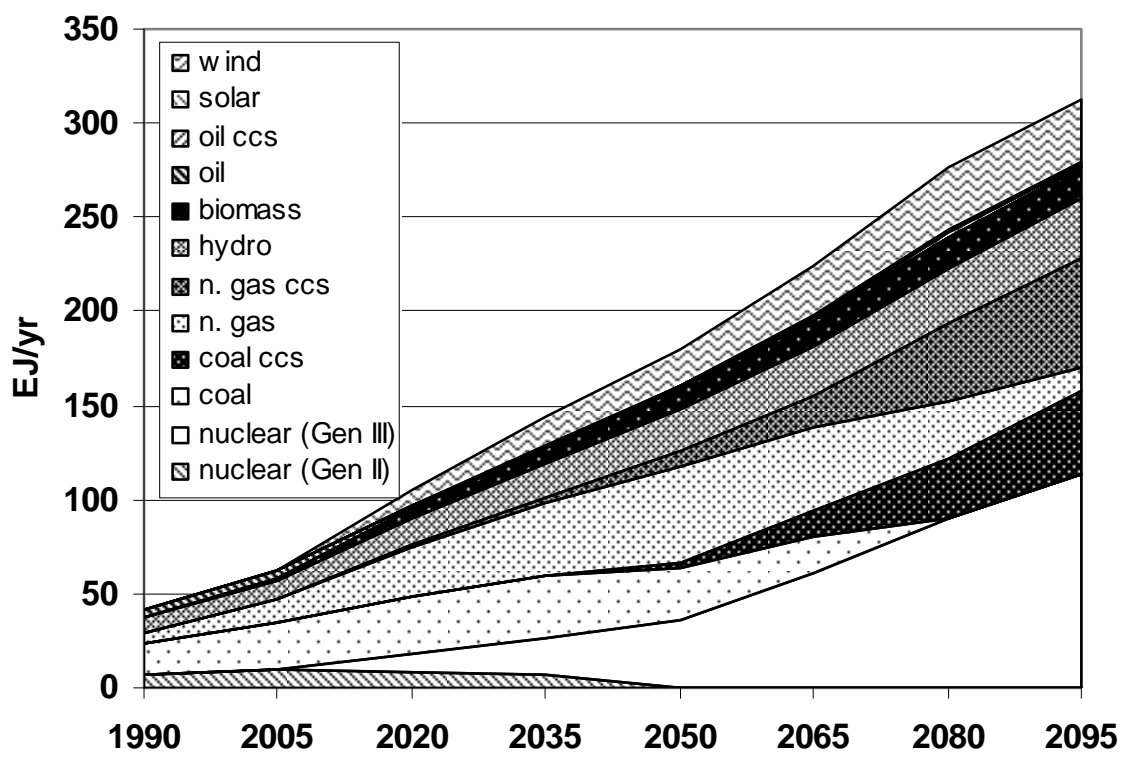

Figure 4-4

Mix of Global Electricity Generation with $\mathrm{CO}_{2}$ Stabilized at $550 \mathrm{ppm}$

The rising value of carbon in the stabilization scenarios has the effect of shifting resources from other parts of the economy to emissions mitigation. That shift incurs an economic cost to society. We have computed that cost for the cases in which nuclear power, existing and new, is available to the economy. To estimate the value of nuclear technology to the economy we must create an alternative case, one in which new nuclear power is not available. We refer to this case as the nuclear moratorium case and the cost of stabilizing $\mathrm{CO}_{2}$ concentration is significantly higher if nuclear technology is unavailable. The difference between the presence and absence of nuclear technology is the inferred value to society of the nuclear technology in stabilizing $\mathrm{CO}_{2}$ concentrations. Calculated global economic costs ${ }^{34}$ and value of nuclear technology are given in Figure 4-5 Panel A and Panel B.

The cost of concentration stabilization and value of nuclear power is closely tied to the $\mathrm{CO}_{2}$ concentration that is chosen. The lower the $\mathrm{CO}_{2}$ concentration is, the higher the cost. Similarly, the lower the $\mathrm{CO}_{2}$ concentration is, the higher the value of nuclear power technology. It is worth noting that these economic values, Figure 4-5 Panel B, are denominated in trillions of 2005 USD.

\footnotetext{
${ }^{34}$ Costs are calculated by discounting annual costs at five percent per year and summing over the period 2095 to 2005.
} 
In the $550 \mathrm{ppm}$ Scenario, the value is nearly 0.8 trillion 2005 USD, and in the tighter $450 \mathrm{ppm}$ Scenario, the value is nearly 2.6 trillion 2005 USD. In comparison, the current US GDP is 13 trillion USD. Thus, the value of nuclear power technology in limiting $\mathrm{CO}_{2}$ concentrations has tremendous potential benefit to society.

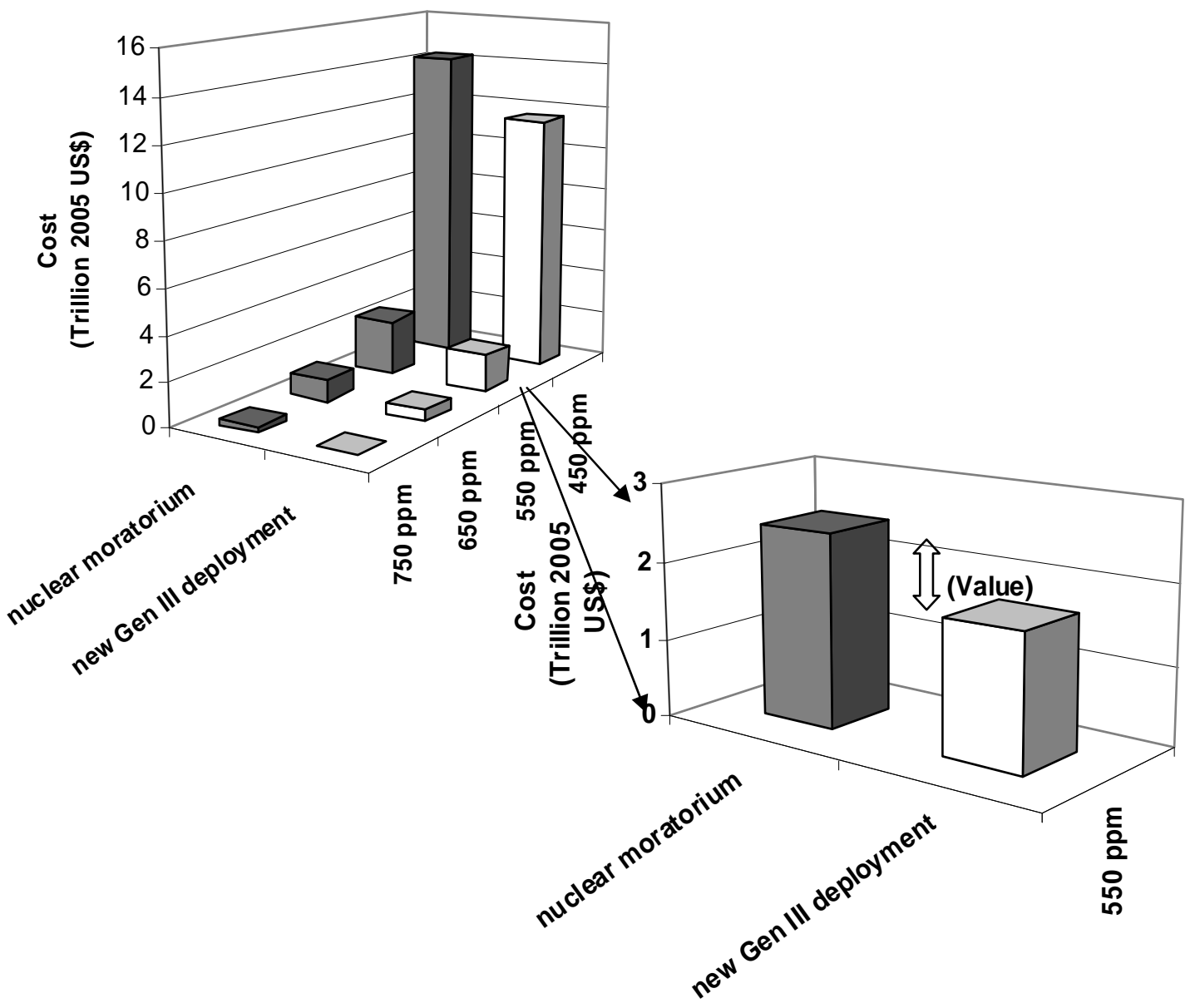

Figure 4-5 Panel A

Global Economic Cost of $\mathrm{CO}_{2}$ Stabilization with and without New Nuclear Deployment for a Range of Concentration Targets 


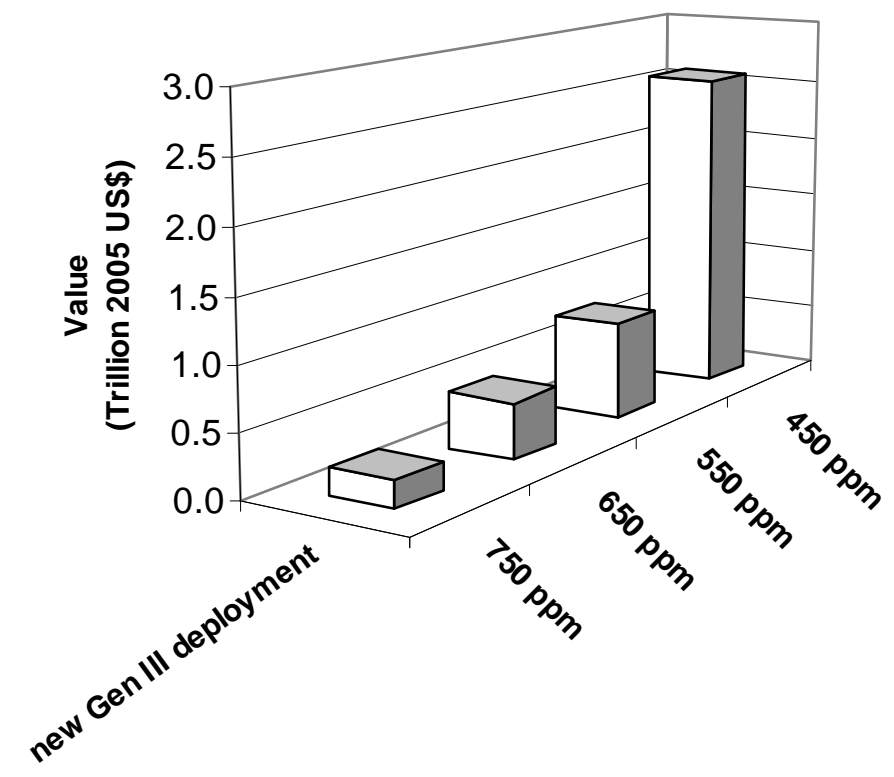

Figure 4-5 Panel B

Global Economic Value of New Nuclear Power Deployment in Stabilizing $\mathrm{CO}_{2}$ Concentrations

\section{Uncertainty of Competing Technologies}

The role of nuclear technology in stabilizing $\mathrm{CO}_{2}$ concentrations could be either larger or smaller than computed in the preceding section. One of the most important factors influencing that role is the success of the competition. In this section we explore the implications for the value of nuclear energy if fossil fuel CCS technologies are not available.

While there are many active programs investigating the potential of CCS technologies, uncertainties remain for their implementation. Estimates of potential geologic storage reservoir capacities have demonstrated that there is no meaningful global constraint, though several important regions such as Japan and Korea appear to have very little capacity. ${ }^{35}$ However, the ability to remove $\mathrm{CO}_{2}$ from exhaust gas streams is a well known but expensive technology, and full scale demonstration of CCS technologies have yet to be completed. More difficult to assess is whether geologic storage systems can be constructed and demonstrated to have $\mathrm{CO}_{2}$ leakage rates that are socially acceptable. Furthermore, institutions to recognize $\mathrm{CO}_{2}$ capture and storage within an emissions control regime with a strong verification program need to be developed. For these reasons, the availability of CCS technologies remains uncertain. ${ }^{36}$

When CCS technologies are unavailable, there are fewer options for power generation under climate constraints. Nuclear power becomes one of the few remaining competitive options for power generation. Figure 4-6 Panels A and B show the increased global generation of nuclear

\footnotetext{
35 See note 16.

${ }^{36}$ Dooley, JJ, RT Dahowski, CL Davidson, MA Wise, N Gupta, SH Kim, EL Malone. 2006. Carbon Dioxide Capture and Geologic Storage, Global Energy Technology Strategy Program (GTSP), Battelle, Joint Global Change Research Institute, College Park, MD.
} 
electricity for alternative concentration scenarios. Significantly more nuclear power is deployed in comparison to when CCS is available, and nuclear power becomes the largest single source of global electricity under all stabilization scenarios. Over $220 \mathrm{EJ} / \mathrm{yr}$ of nuclear electricity is generated by 2095 in the 450 ppm Scenario, representing a tripling of the Reference Scenario nuclear generation. The corresponding nuclear market share of electricity reaches 70 percent. In the $550 \mathrm{ppm}$ Scenario, nearly $180 \mathrm{EJ} / \mathrm{yr}$ of nuclear electricity is generated by 2095 corresponding to a power market share of 60 percent.

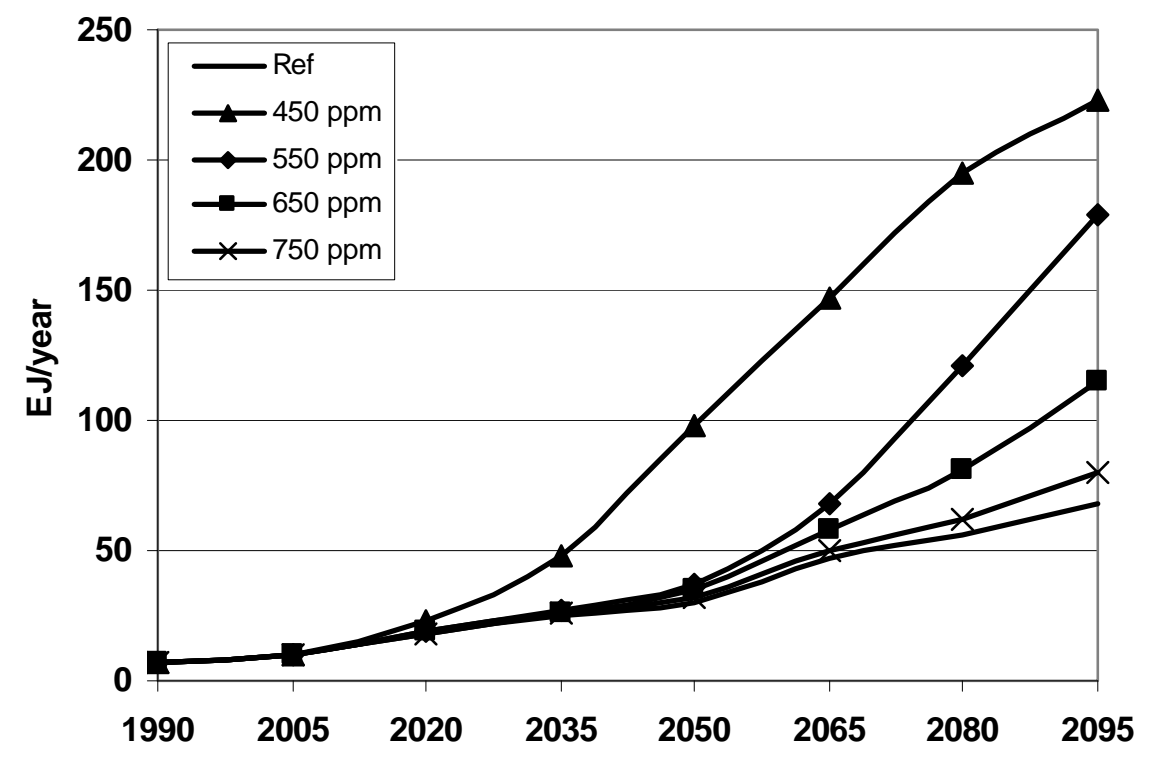

Figure 4-6 Panel A

Global Nuclear Electricity Generation without CCS for Alternative $\mathrm{CO}_{2}$ Stabilization Scenarios (Reference, and $450,550,650$, and $750 \mathrm{ppm}$ ) 


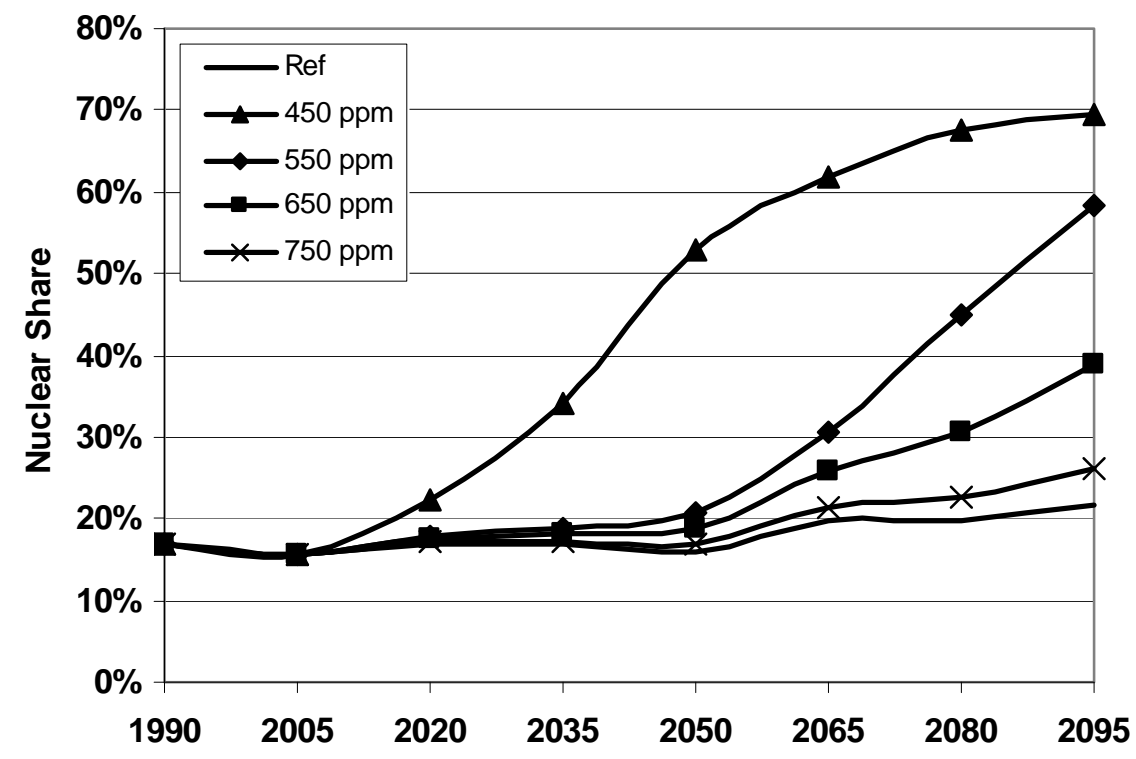

Figure 4-6 Panel B

Nuclear's Share of Global Electricity Generation without CCS for Alternative $\mathrm{CO}_{2}$ Stabilization Scenarios (Reference, and 450, 550, 650, and 750 ppm)

Limited options for low carbon or carbon free power generation imply that the cost for achieving any stabilization regime is higher. The marginal value of adding a nuclear option is therefore increased when CCS is not available. Comparison of the value of nuclear with and without CCS is shown in Figure 4-7. Although higher in all cases when CCS is unavailable, the value of nuclear is disproportionately higher at lower $\mathrm{CO}_{2}$ concentrations. In the $550 \mathrm{ppm}$ Scenario, nuclear's value is over 1.1 trillion 2005 USD and nearly fifty percent greater than the case with CCS, while in the $450 \mathrm{ppm}$ Scenario nuclear's value is 7.7 trillion 2005 USD and three times the value when CCS is available. Considering that nuclear technologies are already a significant, mature and growing source of power today, the value of nuclear energy in mitigating carbon emissions will remain great whether CCS is available or not. 


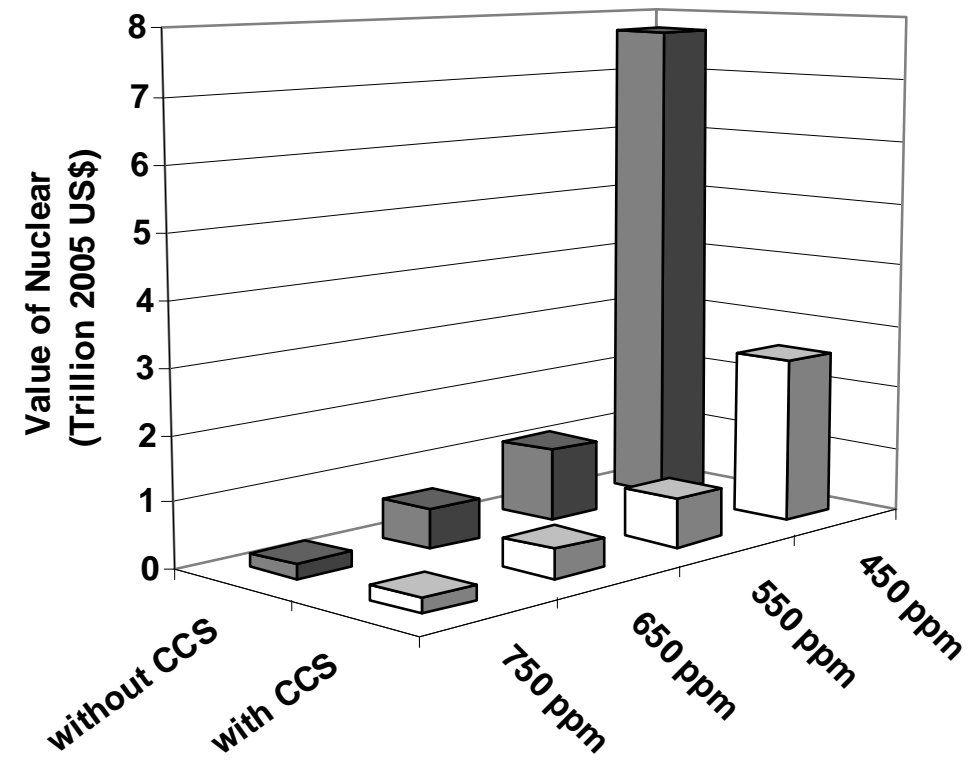

Figure 4-7

Global Economic Value of New Nuclear Deployment with and without CCS 


\section{5}

\section{CHALLENGES FOR THE GREATER USE OF NUCLEAR ENERGY}

In this analysis, access to new nuclear power technologies is available to all modeling regions. Each region is able to deploy new nuclear power plants to the degree allowed by the competition in the power market. This results in significant deployment of nuclear plants from nations that currently have little or no nuclear power capacity but are experiencing significant growth in the demand for electricity over the long-term. On the other hand, in those regions with large nuclear capacity today but slower growth in the demand for electricity, many new reactors are deployed replacing those reaching the end of their lifetimes, as well as for meeting the additional demand for electricity in the long-term. The response to climate change further encourages the growth in power technologies that do not result in GHG emissions, and nuclear power is expected to be an increasingly important part of the global energy system. However, responding to climate change requires unprecedented changes to the nuclear energy system. The scale of change required for the potential expansion of nuclear deployment worldwide presents challenges to all aspects of the nuclear energy system. We explore some of these challenges below.

\section{Nuclear Infrastructure and Proliferation}

Nuclear power could be deployed at large scale and distributed widely throughout the world under climate constraints as a solution to mitigate emissions of $\mathrm{CO}_{2}$. Such a scenario will place greater demands on the global nuclear infrastructure and raise proliferation concerns.

In the Reference Scenario without any carbon constraints, the number of nuclear reactors deployed worldwide grows six-fold from today to more than 2,500 nuclear reactors by the end of the century. In the $450 \mathrm{ppm}$ Scenario (with CCS), the projection of nuclear reactors deployed doubles that of the Reference Scenario throughout the second half of the century and exceeds 4,500 reactors by the end of the century. Even in the $550 \mathrm{ppm}$ Scenario (with CCS), the number of reactors deployed exceeds 4,000 reactors by the end of century, although most of the growth in deployment occurs in the latter half of the century. Figure 5-1 displays the number or nuclear reactors deployed globally for all $\mathrm{CO}_{2}$ concentration scenarios.

While the carbon constraints do not significantly affect the total global production of electricity from the reference case, greater reliance on the use of nuclear energy implies a major shift in the power market. Achieving the above numbers of nuclear deployment requires a global nuclear infrastructure capacity sufficient for constructing from tens to hundreds of reactors per year for the remainder of the century. Figure 5-2 provides a range of new reactor deployment for each 15-year time period for all scenarios. Construction and deployment range from 400 reactors per period in the near-term to as high as 1,500 reactors per period by the end of the century with climate constraints. 
Currently, there are 439 reactors installed in 31 countries. 34 reactors are under construction in 11 countries, 81 reactors are planned and approved in 17 countries, and 223 reactors are proposed in 27 countries but do not have firm commitments. ${ }^{37}$ In total, this represents 338 reactors currently being built, planned, or under consideration around the world. If all proposed reactors are built, the total number of reactors worldwide, involving 38 countries, could reach 778. ${ }^{38}$ This is approximately 150 reactors fewer than the total number of reactors in year 2035 of our Reference Scenario. The response to climate change implies a sustained and significantly ramped-up construction schedule that is several-fold greater than the currently proposed number of reactors throughout the $21^{\text {st }}$ century.

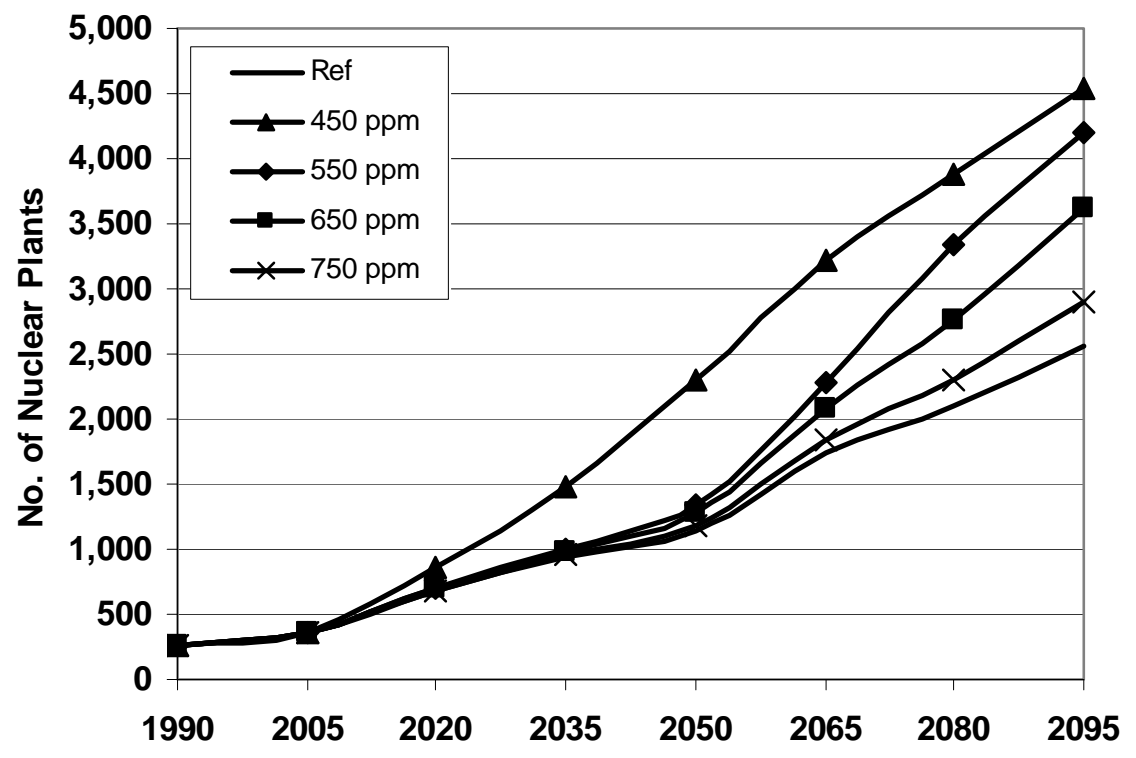

Figure 5-1

Total Number of Nuclear Power Plants in Operation (1000 MWe each with 0.85 capacity factor)

${ }^{37}$ http://www.world-nuclear.org/info/reactors.html

${ }^{38}$ The total is less than 778 if reactors decommissioned after 2007 are not included. 


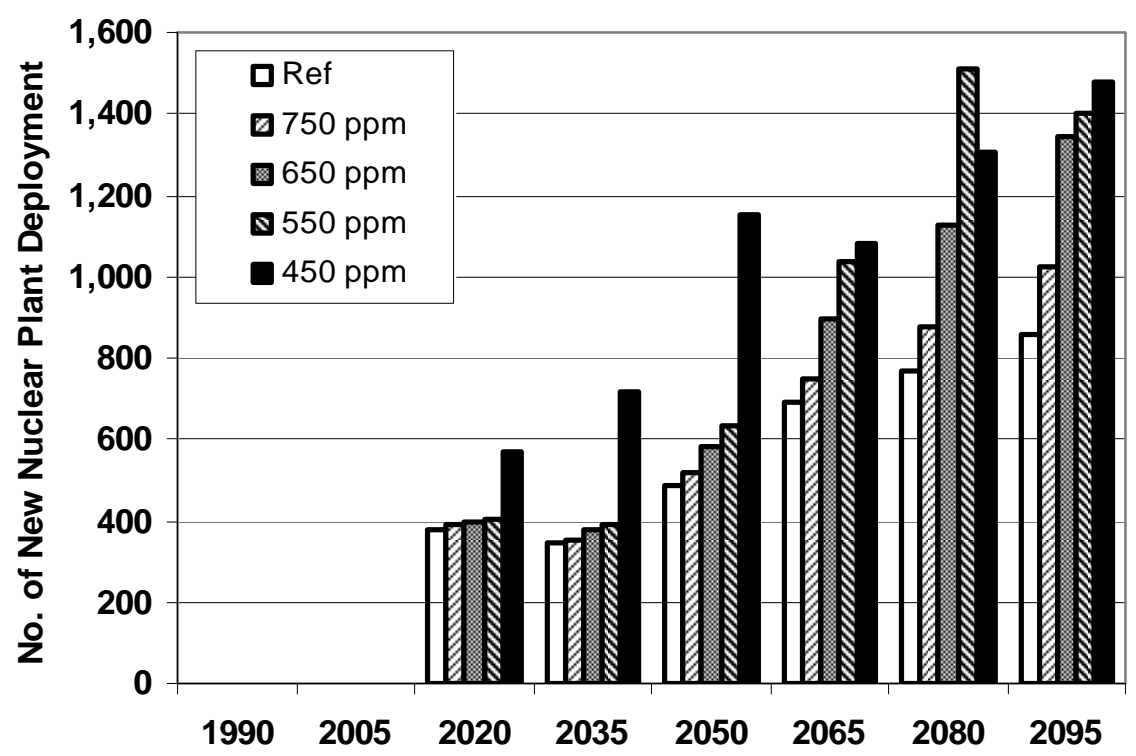

Figure 5-2

Number of New Nuclear Power Plant Deployment per 15 Year Period (1000 MWe each with 0.85 capacity factor and lifetime of 60 years)

Over time, nuclear power becomes increasingly a global energy technology. The distribution of nuclear power plants around the world shifts from the current Annex I nations (OECD plus Former Soviet Union and Eastern Europe) ${ }^{39}$ to Non-Annex I nations ${ }^{40}$. By 2035, more than half of the global nuclear electricity is generated in Non-Annex I nations. That share rises to nearly 75 percent by 2095 (see Figure 5-3 Panel A). The relative distribution of nuclear deployment between Annex I and Non-Annex I nations remain similar across all concentration scenarios, although the use of nuclear energy increases with lower $\mathrm{CO}_{2}$ concentration targets. As shown in Figure 5-3 Panel B for the 550 ppm Scenario, 3,100 Gigawatt electric (GWe) of the total 4,200 GWe global nuclear capacity is installed in Non-Annex I regions by the end of the century.

The significantly increased deployment of nuclear plants in Non-Annex I regions in these scenarios highlights the potential trade and transfer of nuclear technologies and movement of nuclear materials from traditional nuclear powers to new nuclear power states.

\footnotetext{
${ }^{39}$ Annex I refers to a list of nations in the UNFCCC 1 that includes members of the OECD plus the former Soviet Union and Eastern Europe.

${ }^{40}$ All other nations of the world not including Annex I.
} 


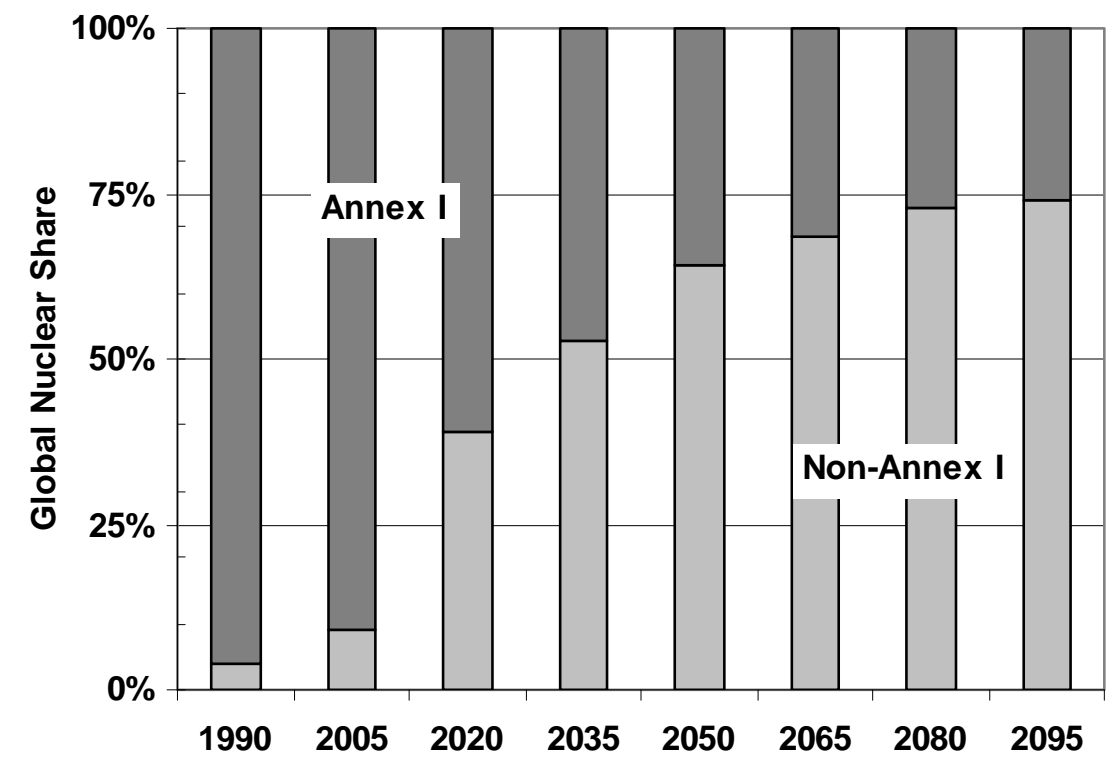

Figure 5-3 Panel A

Share of Global Nuclear Electricity Generation by Annex I and Non-Annex I Regions for 550 ppm Scenario

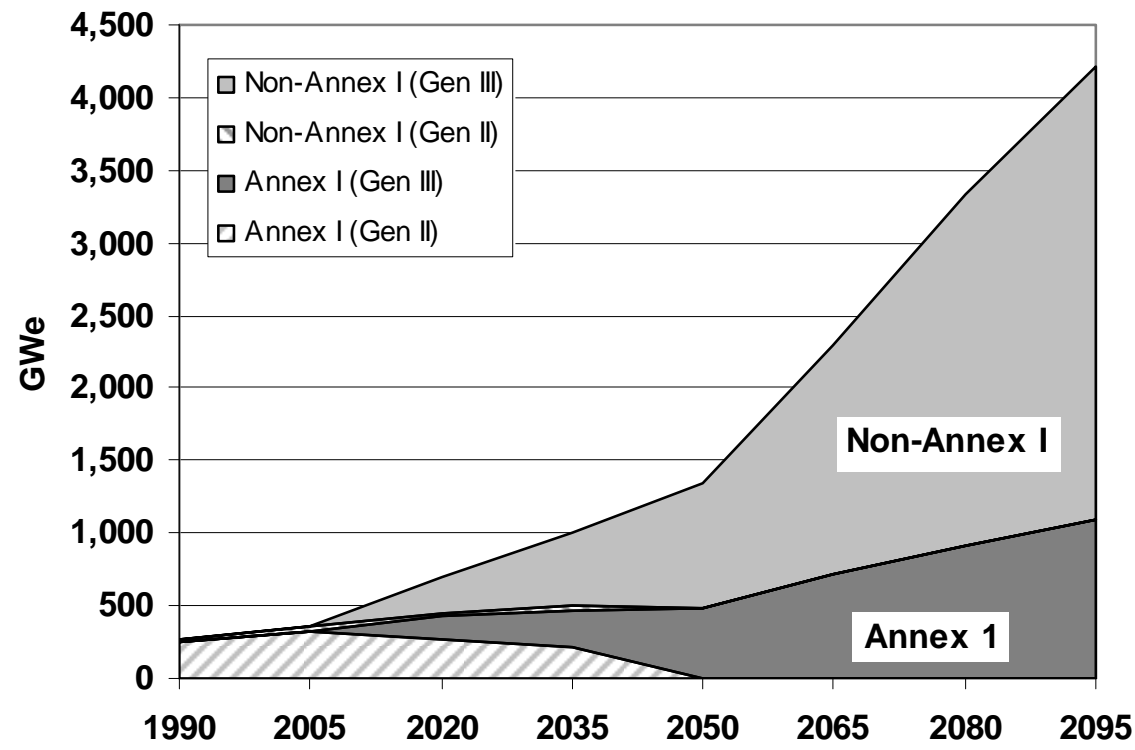

Figure 5-3 Panel B

Nuclear Power Capacity by Annex I and Non-Annex I Regions for 550 ppm Scenario (0.85 capacity factor)

\section{Natural Uranium Availability}

The availability and access to uranium is a potential concern for the global expansion of nuclear power. Although consumption of natural uranium exceeds the Redbook estimates in all of the modeling scenarios after the middle of the century, the high cost of the uranium ore is not an 
obstacle to nuclear's growth. Uranium ore costs represent an incremental fraction of the cost of electricity from nuclear power. In these scenarios, uranium ore costs as a percentage of the cost of nuclear electricity range from 2 to 10 percent at most.

Figure 5-4 Panel A shows the cumulative uranium production for all climate scenarios including the Reference Scenario. The quantities and prices in Figure 5-4 are based on the PPM uranium supply curve and the once-through fuel cycle described above. By 2095, cumulative uranium extraction reaches 25 MTU in the Reference Scenario and 43 MTU in the 450 ppm Scenario. Redbook estimates for uranium availability total 14.4 MTU, and in all scenarios, the consumption of uranium exceeds the Redbook estimates soon after the middle of the century.

The corresponding price of uranium is shown in Figure 5-4 Panel B. Uranium ore prices more than triple the 2005 price of approximately $\$ 40 / \mathrm{kgU}$ and rise to more than $\$ 130 / \mathrm{kgU}$ in the Reference Scenario and $\$ 170 / \mathrm{kgU}$ in the $450 \mathrm{ppm}$ Scenario. Nuclear power remains competitive with high ore costs, however. Additionally, the market is not static and competing fossil power plants face the additional burden of carbon prices under climate policies.

While the uranium ore price in itself is not an obstacle to nuclear expansion, the availability and access to uranium could pose significant challenges. Redbook estimates consists of 4.6 MTU of Known Conventional Resource, 2.3 MTU of Estimated Additional Resource (category II) and 7.5 MTU of Speculative Resource. For all scenarios, known conventional resources are exhausted by 2020. The ability to produce from Estimated Additional Resource (category II) and Speculative Resource is therefore necessary by 2020, and discovery of uranium resources beyond those in the Redbook estimates are required by the middle of the century to support the growing use of nuclear energy as projected in these scenarios.

Long lead-times, in the order of decades, with sufficient infrastructure development are required to ensure continuous supply of uranium. The bulk of the resources in the Redbook estimates are distributed to a dozen or so countries with significant known and speculative resources located in Australia, Brazil, Canada, Kazakhstan, Mongolia, Namibia, Niger, Russian Federation, South Africa, Ukraine, Uzbekistan, and United States. Significant trade in uranium is expected as the use of nuclear energy becomes increasingly global and regions of future demand and supply do not coincide. Inability to bring alternative sources of uranium into production in a timely manner could lead to supply shortages along with high prices. 


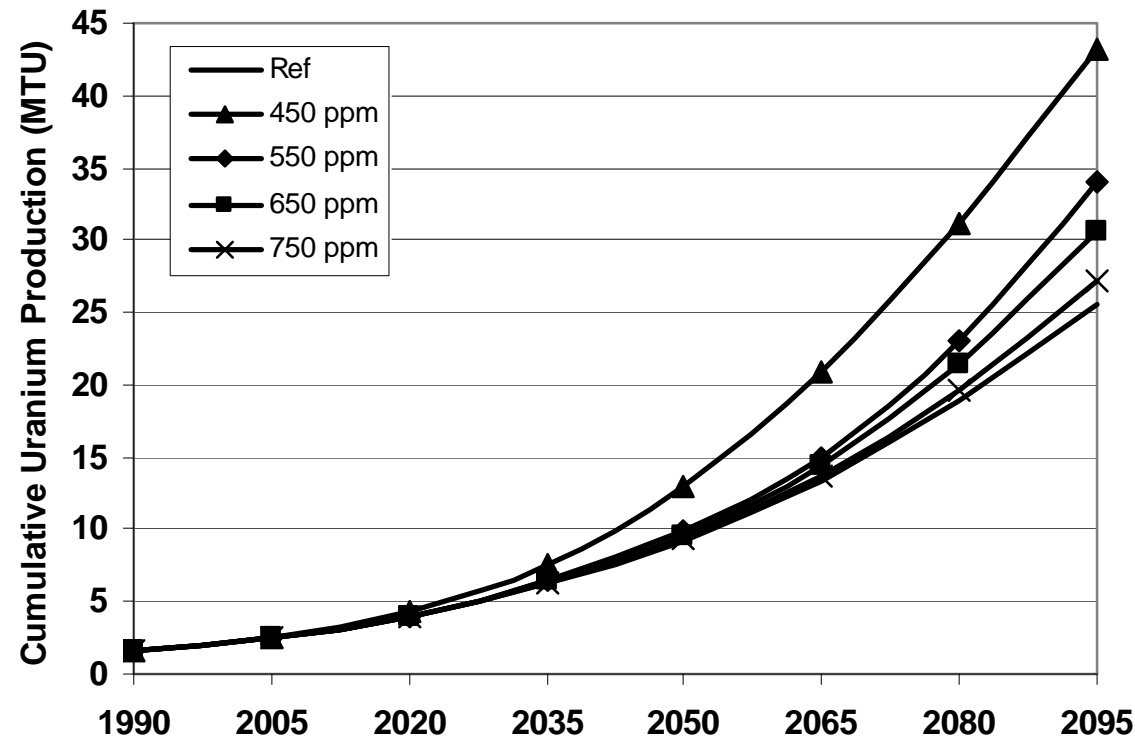

Figure 5-4 Panel A

Cumulative Global Uranium Production (Million Tons of U)

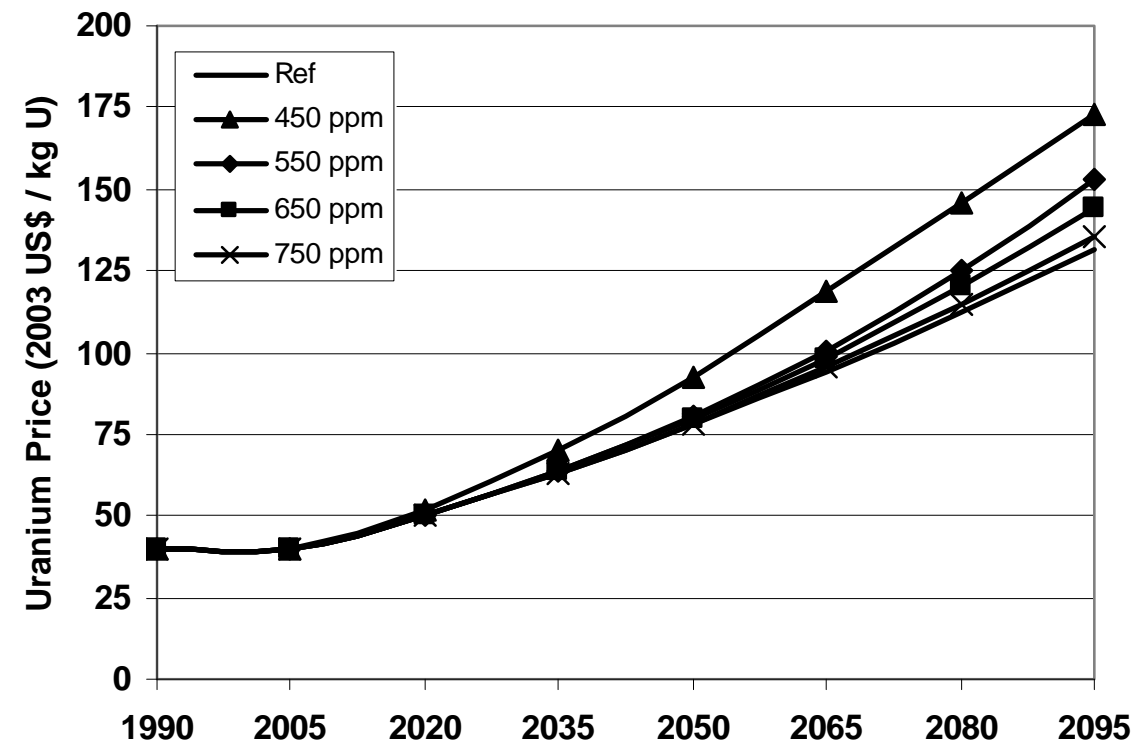

Figure 5-4 Panel B

Uranium Ore Price (2003 US \$ / kg U)

Sensitivity studies on alternative uranium supply curves illustrate that the availability of uranium, and not its price, is the key factor in the future use of nuclear power based on the oncethrough fuel cycle. We use the long term uranium supply estimates by Schneider and Sailor to 
explore the impact of uranium price on nuclear growth. ${ }^{41}$ Several additional supply curves, Optimistic, Conservative, FCCCG(1) ${ }^{42}$, and Pure KCR, as well as the PPM supply curve used in this study, are shown in Figure 5-5 Panel A. All of the supply curves are developed from first principles based on the relationships between the abundance of uranium in the earth's crust as a function of concentration and correlation of concentration with extraction cost. Differing assumptions on the correlations among abundance, concentration and extraction cost result in the quantity of uranium available at a given price to vary by several orders of magnitude. The most conservative supply curve, Pure KCR, is a fit of the simple crustal model to the Redbook's Known Conventional Resource data and essentially limits the availability of uranium to known conventional resources. According to Schneider and Sailor, the Pure KCR curve represents an unrealistic portrayal of the relationship between uranium supply and price.

Figure 5-5 Panel B shows the resulting sensitivity of global nuclear electricity generation for the next century in the Reference Scenario to the alternative uranium supply curves of Figure 5-5 Panel A. With the exception of the Pure KCR curve, alternative assumptions of uranium supply have virtually no impact on the long-term growth and use of nuclear energy. Although the resulting price of uranium in the Optimistic and FCCCG(1) cases differ by nearly a factor of three (difference of $\$ 137 / \mathrm{kgU}$ ), the difference in the global generation of nuclear electricity at the end of the century is only 15 percent. Only an extremely pessimistic and unrealistic assumption about the availability of uranium, as in the Pure KCR case, curtails the long-term use of nuclear energy.

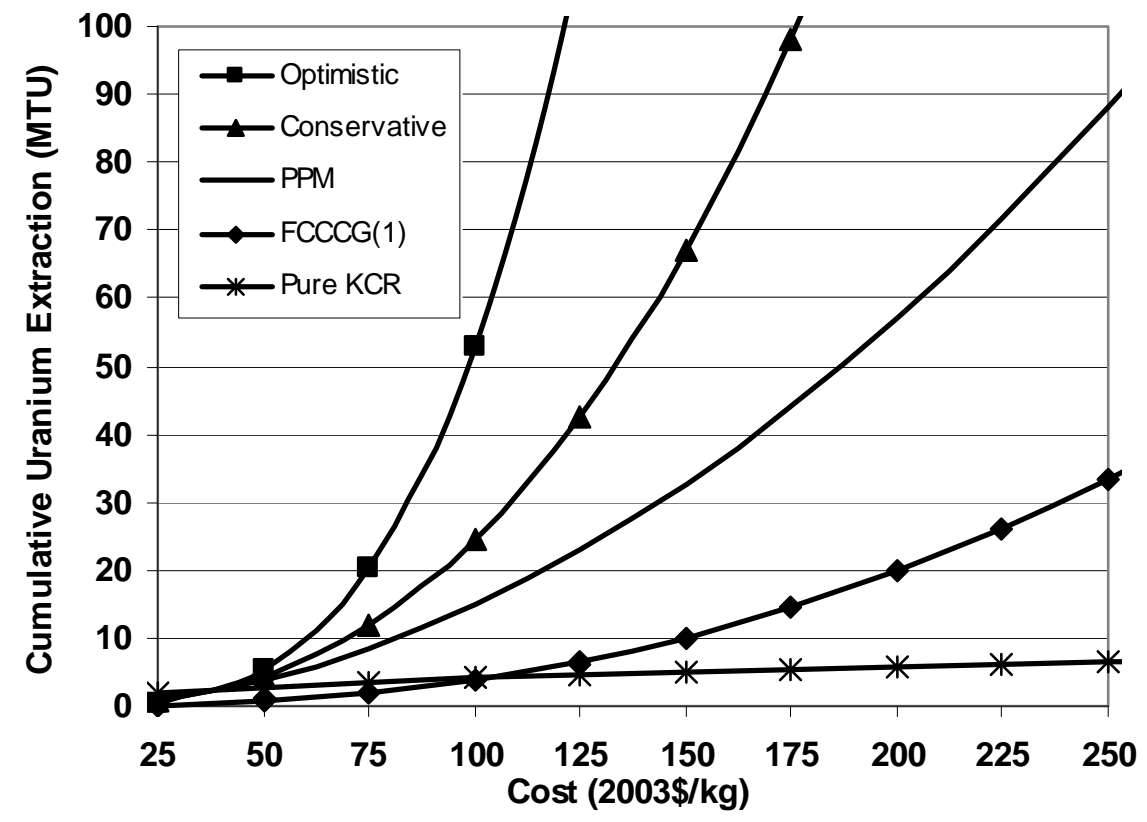

Figure 5-5 Panel A

Alternative Uranium Supply Curves (Optimistic, Conservative, PPM, FCCCG(1), and Pure KCR)

\footnotetext{
${ }^{41}$ Schneider and Sailor, see note 23.

${ }^{42}$ Fuel Cycle Crosscut Group (FCCCG), see note 26.
} 


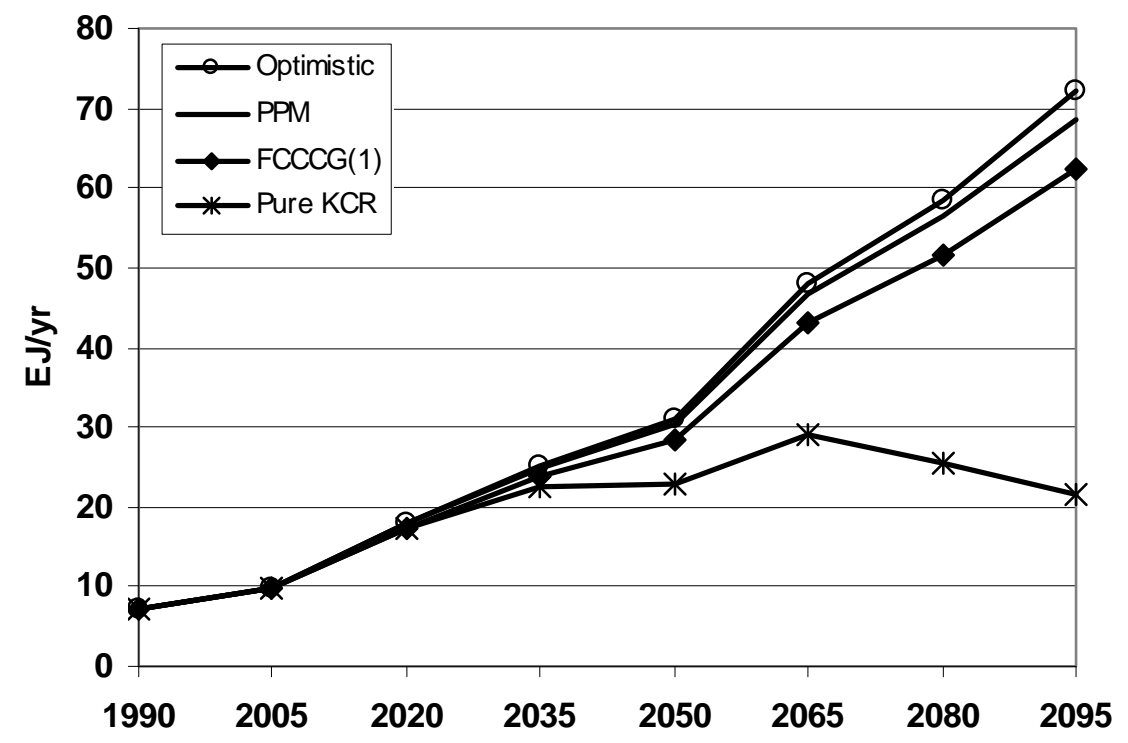

Figure 5-5 Panel B

Sensitivity of Global Nuclear Electricity Generation with Alternative Uranium Supply Curves (Optimistic, PPM, FCCCG(1), and Pure KCR; Conservative curve removed for clarity )

\section{Nuclear Waste Accumulation and Disposal Capacity}

One of the most difficult challenges for the global expansion of nuclear energy is nuclear waste disposal. No operating permanent high-level waste disposal facility exists anywhere around the world today, and resolution on the long-term fate of accumulating high-level wastes remains uncertain in every nation that utilizes nuclear power. Creation, implementation and realization of a safe and viable permanent waste disposal strategy is likely to become a more pressing concern for the world, particularly if nuclear energy is to play a significant role in addressing climate change.

Nuclear waste is an inevitable byproduct of nuclear energy production, and the continued use and expansion of nuclear energy will result in the growing accumulation of nuclear waste worldwide. An accounting of spent fuel waste generated in the Reference and $\mathrm{CO}_{2}$ stabilization scenarios is shown in Figure 5-6. Roughly 150 thousand metric tons of spent fuel has been generated globally thus far. Nuclear energy use in the Reference Scenario with a once-through fuel cycle accumulates 2.4 million tons of spent fuel by 2095. In the $450 \mathrm{ppm}$ Scenario with significantly greater use of nuclear energy, cumulative spent fuel generation amounts to 4.1 million tons by 2095. Taking the full lifetime of reactor operation into consideration, spent fuel generation will certainly exceed these amounts even if no additional nuclear plants are deployed after 2095.

Although the spent fuel generated in these scenarios is several orders of magnitude more than what has been generated thus far, it is difficult to gauge whether these quantities represent an unmanageable scenario for waste disposal. That answer depends in part, on the potential 
capacity and realization of future waste disposal facilities, as well as the acceptance and realization of recycling and waste reduction efforts. ${ }^{43}$ If we use the legislated capacity of the proposed US Yucca Mountain repository (70 thousand tons of spent fuel) ${ }^{44}$ as the basis for comparison, 35 to 59 Yucca Mountain repositories will be needed globally by the end of the century for the direct disposal of spent fuel from the Reference and $450 \mathrm{ppm}$ scenarios, respectively. On the other hand, if the maximum physical capacity of the Yucca Mountain repository ( $\sim 70$ thousand tons of spent fuel) $)^{45}$ is used, then 4 to 7 Yucca Mountain repositories are sufficient for global spent fuel disposal over the century.

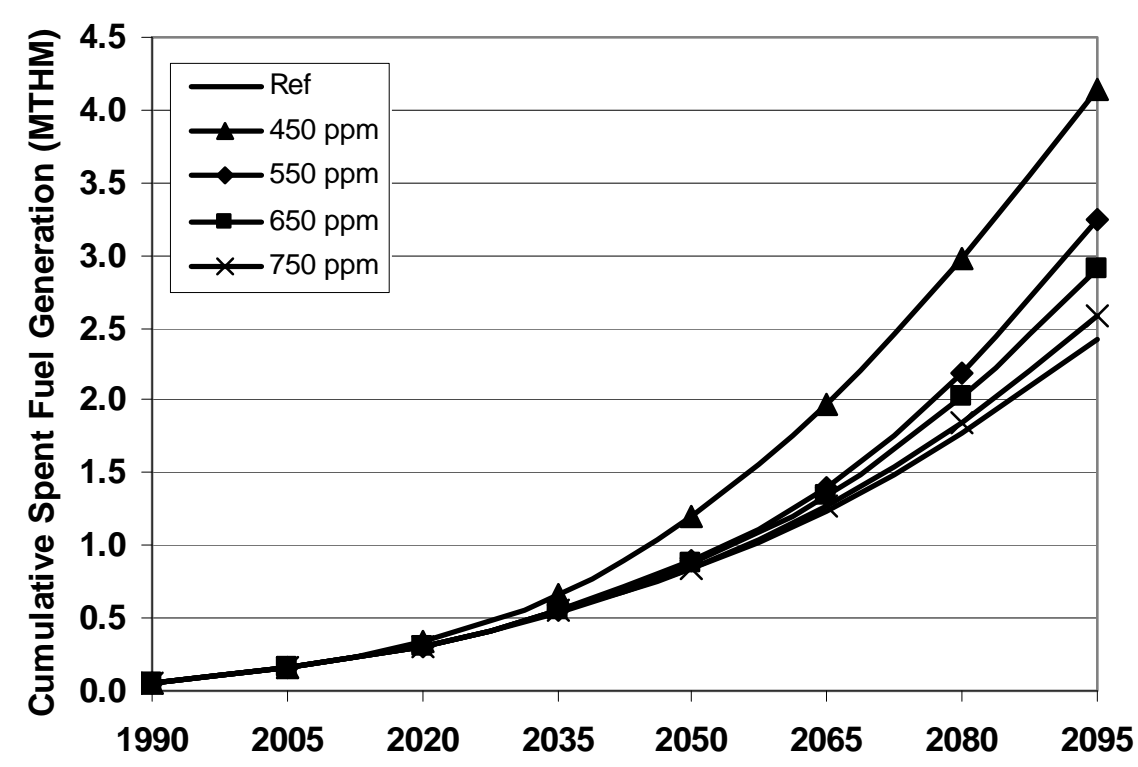

Figure 5-6

Cumulative Global Spent Fuel Generation (Million Tons of Heavy Metal - MTHM)

The issues of nuclear waste disposal to some degree are analogous to the front-end issues of uranium supply discussed above. The cost of spent fuel disposal is not likely to be the limiting factor for the expanded use of nuclear energy, but rather the availability, access and capacity of permanent waste disposal repositories. We investigated the impact of waste disposal cost on nuclear energy use by varying the cost of disposal. Figure 5-7 shows the sensitivity in the global generation of nuclear electricity to disposal cost in the Reference Scenario. A doubling of the fixed disposal cost from $400 \$ / \mathrm{kg}$ to $800 \$ / \mathrm{kg}$ on spent fuel of new nuclear plants has a marginal impact on the global generation of nuclear electricity. A doubling of the waste disposal cost results in a four percent reduction in global nuclear generation by 2095. A five-fold increase in the disposal cost to $2,000 \$ / \mathrm{kg}$ and even an order of magnitude increase in the disposal cost to

\footnotetext{
${ }^{43}$ We recognize that several nations today have pursued a program of nuclear fuel recycling for the re-use of fissile materials. No nation has yet to incorporate "burner” reactors for the reduction of minor actinides, however.

44 “Nuclear Waste Policy Act of 1982”, Public Law No. 97-425, 96 Stat. 2201, January 7, 1983.

${ }^{45}$ Electric Power Research Institute (EPRI). 2006. Program on Technology Innovation: Room at the Mountain Analysis of the Maximum Disposal Capacity for Commercial Spent Nuclear Fuel in a Yucca Mountain Repository., Palo Alto, CA: 1013523.
} 
4,000 \$/kg on spent fuel does not hinder the growth in nuclear energy use worldwide, although global nuclear electricity generation is reduced by 16 and 32 percent, respectively, by 2095 .

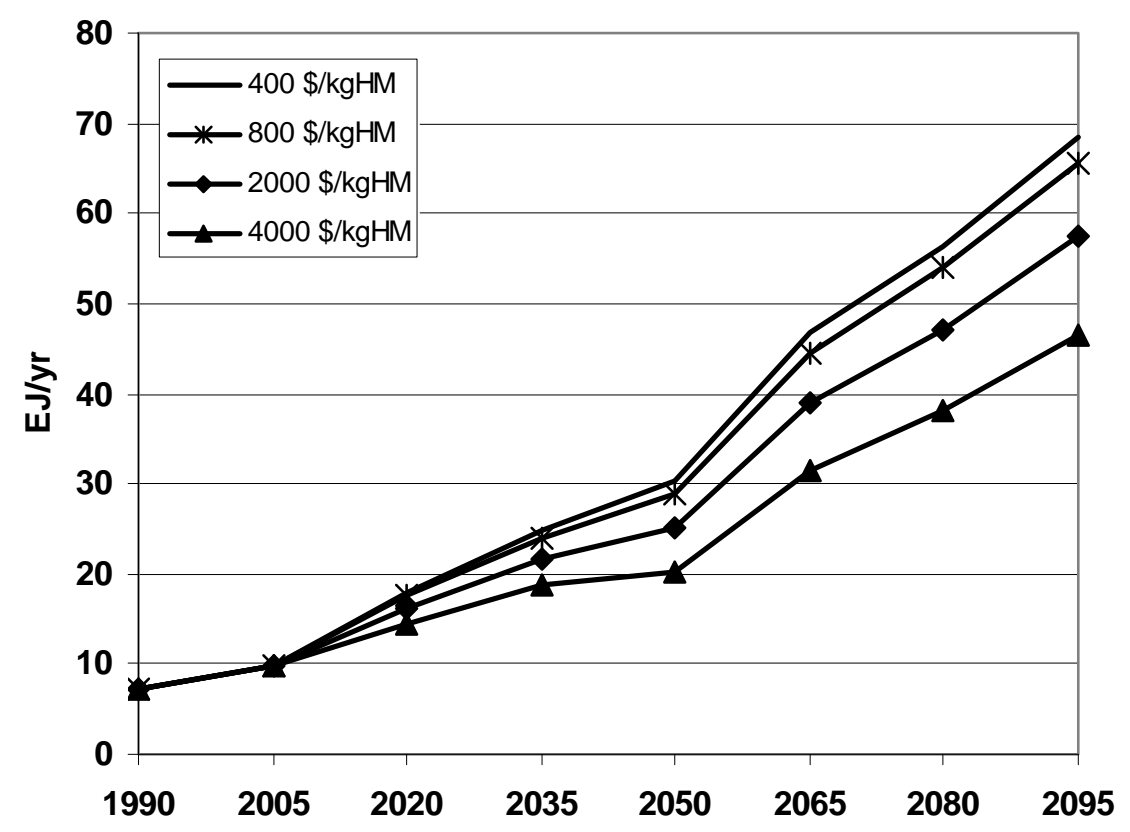

Figure 5-7

Global Nuclear Electricity Generation (Waste Disposal Charge of 400, 800, 2000, and 4,000 \$/kgHM)

\section{Global Nuclear Energy Partnership}

The challenges for the global use of nuclear energy as identified in this study are being addressed through international programs such as the Global Nuclear Energy Partnership (GNEP) led by the US administration and Department of Energy. ${ }^{46}$ The purpose of GNEP is to "develop worldwide consensus on enabling expanded use of economical, carbon-free nuclear energy to meet growing electricity demand”.

GNEP envisions a global system for nuclear energy use in which nations with secure, advanced nuclear capabilities provide fuel services to other nations who agree to use nuclear energy for power generation purposes only. At the heart of this vision is a closed fuel cycle model that promotes non-proliferation and requires the development and deployment of technologies that enable recycling and consumption of long-lived radioactive wastes. The benefit of such a fuel cycle model is the greater utilization of nuclear fuels and resources, minimization of nuclear wastes, and potential reduction of proliferation concerns such that nuclear energy use can be greatly expanded worldwide while minimizing the required number of geologic waste repositories.

While the economic costs of nuclear power technologies and related fuel cycle infrastructures are important considerations in the use of nuclear energy, we have shown that costs alone are not the limiting factor in the expanded use of nuclear energy. Issues of nuclear proliferation, fuel

\footnotetext{
${ }^{46}$ www.gnep.energy.gov
} 
availability, and waste disposal transcend the issues of costs. If nuclear energy is to play a major role in the global energy system, particularly in response to climate change, these issues must be addressed. Programs such as GNEP represent an important step in this direction. Future studies investigating the impact of advanced nuclear technologies as identified and envisioned by GNEP in a long-term global economic context will help clarify the value of advanced nuclear technologies and GNEP for the expanded use of nuclear energy and for addressing climate change. 


\section{6 \\ CONCLUSIONS}

This report has explored the potential value of nuclear power and challenges for its large scale deployment in a climate-constrained world. The first and most important observation is that the potential global economic value of nuclear energy to address climate change is denominated in trillions of 2005 USD. The precise value depends on factors such as the concentration to which atmospheric $\mathrm{CO}_{2}$ levels are limited, the economic performance of competing technologies, the availability of uranium and waste disposal facilities, and the character of nuclear energy technology. We have explored the interaction of these factors within the context of a long-term, global energy-economy framework, $\mathrm{O}^{\mathrm{bj}}$ ECTS-MiniCAM.

We have shown that the value of maintaining a nuclear power option in addressing climate could be as high as 2.6 trillion 2005 USD if society limits $\mathrm{CO}_{2}$ concentrations to $450 \mathrm{ppm}$ and 0.8 trillion 2005 USD if society limited $\mathrm{CO}_{2}$ concentrations to $550 \mathrm{ppm}$. The tighter the climate constraint is, the greater the value of a nuclear option in addressing that constraint. Similarly, limited options for competitive carbon-free power technologies increase the value of maintaining a nuclear option. If high cost and uncertainties concerning the permanence of $\mathrm{CO}_{2}$ storage in geologic formations prevent the implementation of fossil fuel carbon capture and storage (CCS) technologies, the value of deploying nuclear power in a climate-constrained world could rise to 7.7 trillion 2005 USD in the 450 ppm case and 1.1 trillion 2005 USD in the 550 ppm case. The value of the nuclear option is disproportionately higher as the target for $\mathrm{CO}_{2}$ concentration becomes more stringent and the options for carbon-free power generation are limited.

While the deployment of nuclear power in a climate-constrained world has tremendous value, the implications of a rapid large-scale deployment of nuclear power pose several challenges. The response to climate change requires that nuclear power is widely utilized in those regions of the world where the growth in the demand for power is increasing. Nuclear power, thus, becomes a global energy technology with potentially 2,500 to 4,500 reactors by the end of the century. A sustained construction schedule of several hundreds increasing to more than a thousand reactors every 15 years is required throughout the century to achieve these numbers. Over time, the majority of worldwide nuclear reactors, nearly 75 percent, is deployed in the current Non-Annex I nations. Limitations on the global infrastructure for new nuclear construction and worldwide proliferation of nuclear technologies and materials are potential concerns.

With the once-through fuel cycle, the total consumption of natural uranium throughout the century exceeds the Redbook estimate of uranium resources in all scenarios. By the end of the century, 25 to 43 MTU of uranium are consumed in the Reference and $450 \mathrm{ppm}$ Scenarios, representing several multiples of the 14.4 MTU total Redbook estimate. Uranium prices rise steadily as demand increases, greater than $\$ 170 / \mathrm{kgU}$ in the $450 \mathrm{ppm}$ Scenario, but the high cost of uranium is not an obstacle to nuclear growth. Several sensitivity cases on alternative uranium supply curves show that their differences have virtually no impact on the global use of nuclear energy for the next century. Uranium ore costs represent an incremental fraction, 2 to 10 percent 
at most in our scenarios, of the cost of electricity from nuclear power. Only an extremely pessimistic or unrealistic scenario of uranium availability results in the decline of nuclear energy use in the $21^{\text {st }}$ century. While uranium prices are less significant, the continuous availability and access to uranium and nuclear fuels are, however, important factors in the global deployment and use of nuclear power.

Inevitably, significant accumulation of spent fuel results from the large scale use of nuclear energy. Nearly 2.4 to 4.1 million tons of spent fuel are accumulated by the end of century in the Reference and $\mathrm{CO}_{2}$ Stabilization scenarios studied. Whether these quantities represent unmanageable levels of high-level waste depends on the global capacity and realization of waste disposal repositories. Assuming direct disposal of spent fuel, the 4.1 million tons of spent fuel accumulated globally in the 450 ppm Scenario would require as many as 59 US Yucca Mountain repositories by the end of the century with a legislated capacity of 70 thousand tons, or as few as 7 US Yucca Mountain repositories with the maximum physical capacity of 570 thousand tons. We emphasize that these are global requirements for nuclear waste disposal. While there are potentially multiple strategies for waste disposal, there is no debate about the real and urgent need for permanent disposal facilities for safeguarding the growing accumulation of high-level wastes. Analogous to the front-end cost for uranium, the cost of waste disposal represents a small fraction of the nuclear electricity cost and is not likely to hinder the growth in the use of nuclear energy. A waste disposal charge that is an order of a magnitude greater than the current charge of one mill per $\mathrm{kWhr}$, approximately 4,000 \$/kg of spent fuel, did not prevent the fivefold increase in the growth of nuclear energy use by the end of the century.

Nuclear power has significant potential value to society for addressing climate change. While the economics of nuclear power matters, non-economic issues of nuclear proliferation, fuel availability and waste disposal transcend the issues of costs. New advances in nuclear technologies and a new vision for the use of nuclear power in a global energy system are needed to realize the potential of nuclear energy. Programs such as the US Global Nuclear Energy Partnership (GNEP) that address these concerns are an important step in this direction. 